\title{
Battery Impedance Measurement Using Sinusoidal Ripple Current Emulator
}

Md. Kamal Hossain

md.k.hossain@uconn.edu

\section{Recommended Citation}

Hossain, Md. Kamal, "Battery Impedance Measurement Using Sinusoidal Ripple Current Emulator" (2017). Master's Theses. 1057. https://opencommons.uconn.edu/gs_theses/1057

This work is brought to you for free and open access by the University of Connecticut Graduate School at OpenCommons@UConn. It has been accepted for inclusion in Master's Theses by an authorized administrator of OpenCommons@UConn. For more information, please contact 


\title{
Battery Impedance Measurement Using Sinusoidal Ripple Current Emulator
}

\author{
Md. Kamal Hossain
}

B.Sc, Rajshahi University of Engineering and Technology, Bangladesh, 2010

\author{
A Thesis \\ Submitted in Partial Fulfillment of the \\ Requirements for the Degree of \\ Master of Science
}

At the

University of Connecticut

2017 


\section{APPROVAL PAGE}

Master's of Science Thesis

Battery Impedance Measurement Using Sinusoidal Ripple Current Emulator

Presented by

Md. Kamal Hossain, B.Sc.

Major Advisor

Dr. Sung-Yeul Park

AssociateAdvisor

Dr. Ali M. Bazzi

Associate Advisor

Dr. Yang Cao

University of Connecticut

2017

ii 


\section{ACKNOWLEDGEMENTS}

At the beginning, all the extol is paid to the Almighty Allah for keeping me alive, giving the knowledge, ability to think, and for helping to finish my thesis work successfully, with His inexhaustible kindness.

I would like to express my whole hearted deep gratitude, immeasurable appreciation and thank everyone who gave me of their valuable time, knowledge and experience to aid the process of completing this thesis. Specially, I wish to offer a lot of thanks to my honorable advisor Dr. Sung-Yeul Park, Associate Professor, Department of Electrical and Computer Engineering, University of Connecticut, Storrs, USA, for his continuous assistance, expertise, encouragement, motivation and incentive guidance throughout the period of this work. During the course of this work he generously gave his time, resource, knowledge and valuable suggestions which helped me to complete the thesis timely and make it reality. I would also like to thank the rest of my committee members: Dr. Ali M. Bazzi, and Dr. Yang Cao, for their insightful comments, encouragement and successfully finished the thesis.

I would also like to give my sincerest thanks to my lab mates Shawn Maxwell, S.M Rakiul Islam, Kevin Bisson and Wei Kou for their assistance in the lab. I want to also express my deep thankfulness to all the others lab members and undergraduate student who helped me during my experimental test. Finally special gratitude goes to my parents and family members, my best wishers for their great sacrifices, moral support, optimistic inspiration and peaceful cooperation. I am lucky to have such an amazing family community in UCONN and I look forward to see you all again.

April, 2017

Author 


\section{LIST OF CONTENTS}

Chapter Content Page

1 Introduction 1

1.1 Background................................................................................... 1

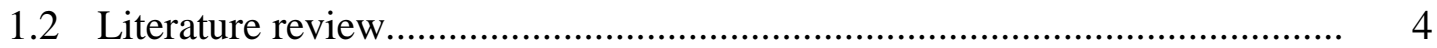

1.3 Problem statements......................................................................... 6

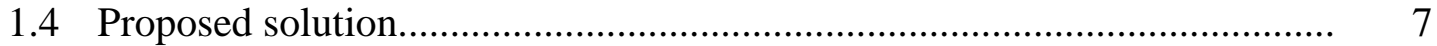

1.5 Thesis outline 8

2 Sinusoidal Ripple Current Charging Emulator 10

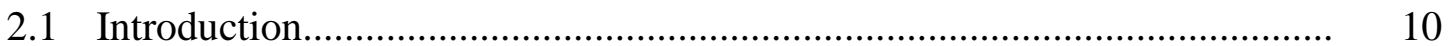

2.2 Configuration of SRC emulator................................................................ 11

2.3 Sinusoidal ripple current profile............................................................. 11

2.4 Sinusoidal ripple current generator..................................................... 12

2.4.1 Ac source perturbation....................................................... 12

2.4.2 Programmable load perturbation.............................................. 14

2.5 Battery ac ripple extraction................................................................ 14

2.6 dSPACE1104 impedance calculation........................................................ 15

3 Design and Hardware Implementation of Filter Sensing Board 16

3.1 Filter sensing board (FSB) ........................................................... 16

3.2 Battery current and voltage sensing.................................................... 17

3.2.1 Current measurement circuit................................................ 17

3.2.2 Voltage measurement circuit............................................... 18

3.3 Decoder and encoder........................................................................ 19

3.4 Filter circuit channel......................................................................... 20

3.4.1 Pass band filter..................................................................... 20

3.4.2 All pass filter.................................................................. 22

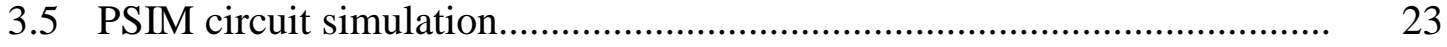

3.5.1 Simulation circuit model...................................................... 23

3.5.2 Simulation result............................................................... 24 
4 Battery AC Impedance Calculation $\quad 25$

4.1 Battery equivalent ac impedance......................................................... 25

4.2 AC impedance extracting method....................................................... 27

4.3 dSPACE1 104 control desk.............................................................. 28

4.3.1 Introduction of dSPACE1 104............................................. 28

4.3.2 Structure of a real-time program............................................ 29

4.4 dSPACE1104 impedance calculation procedure...................................... 30

4.4.1 d-q transformation method................................................ 30

4.4.1.1 Stationary $\alpha-\beta$ to $d-q$ rotating co-ordinate system..... 30

4.4.1.2 Total impedance and phase angle calculation.......... 31

5 Experiment Results 32

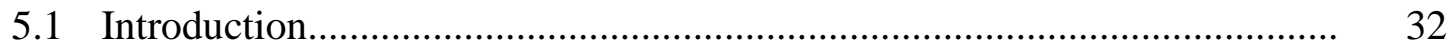

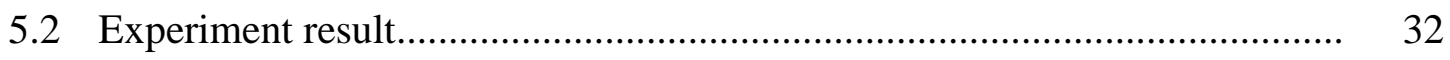

5.2.1 AC source perturbation........................................................ 32

5.2.2 Programmable load perturbation.............................................. 33

5.3 Signal measurement........................................................................ 35

5.3.1 Current sensor output.............................................................. 35

5.3.2 Voltage sensor output........................................................ 36

5.4 Filter circuit test result..................................................................... 39

5.4.1 AC ripple extraction.............................................................. 39

5.4.2 Rotating $\alpha-\beta$ signal procedure................................................ 40

5.5 Impedance measurement result............................................................ 41

$6 \quad$ Conclusion and Further Work 44

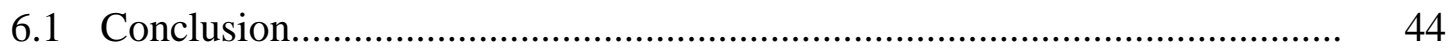

Appendix Content

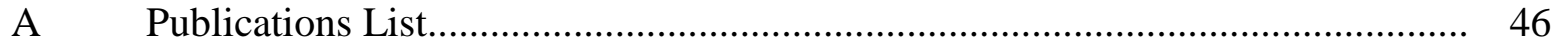

B References List............................................................................. 47

C Filter Circuit Design...................................................................... 50

D Hardware Design and Implementation................................................ 51

E dSPACE1104 Impedance Calculation................................................... 53 


\section{LIST OF FIGURES}

Fig. 1.1 Battery equivalent circuit model 2

Fig. $\quad 1.2$ Nyquist plot of Li-ion call and sectionized equivalent circuit [15] 3

Fig. 2.1 Configuration diagram of SRC emulator 11

Fig. 2.2 Sinusoidal ripple current generator $\quad 12$

Fig. 2.3 Circuit diagram for ac ripple current generator 13

Fig. 3.1 Signal processing of the $\alpha-\beta$ frame of ripple voltage and current 17

$\begin{array}{lll}\text { Fig. } 3.2 & \text { Current sensing circuit [45] } & 18\end{array}$

$\begin{array}{lll}\text { Fig. } & 3.3 & \text { Voltage sensing circuit [47] }\end{array}$

Fig. 3.4 Functional diagram of MC1407B [47] 19

Fig. 3.5 Block diagram of filter circuit for creating $\alpha-\beta$ frame 20

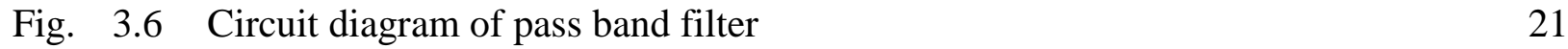

Fig. 3.7 Amplifier and all pass filter 23

Fig. $\quad 3.8$ PSIM simulation model of filter circuit for extracting ac ripple content 24

Fig. $\quad 3.9$ PSIM simulation result (a) low pass (b) band pass and all pass filter 25

Fig. 4.1 dSPACE1104 elements 28

Fig. $\quad 4.2$ Real time control structure of dSPACE 29

Fig. 4.3 dSPACE1104 impedance calculation process 30

Fig. $\quad 5.1$ Experimental set-up for measuring battery ac impedance 33

Fig. $\quad 5.2$ SRC signal generation (a) ac source (b) programmable load perturbation 34

Fig. 5.3 Current sensor output $\quad 35$

Fig. $\quad 5.4$ Experimental waveforms of different voltage sensor 37

Fig. $\quad 5.5$ Experimental result of low pass and difference amplifier 39

Fig. $\quad 5.6$ Experimental result of $\alpha-\beta$ frame of ripple voltage and current $\quad 40$

Fig. $\quad 5.7$ Battery impedance calculation by dSPACE1104 41

Fig. 5.8 Battery real and imaginary impedance under different frequency 42

Fig. D.1 Schematic diagram of low pass, pass band and all pass filter amplifier $\quad 51$

Fig. D.2 Schematic diagram of filter sensing board 51

Fig. D.3 Top view of filter sensing board $\quad 52$ 
Fig. D.4 Bottom view of filter sensing board

Fig. E.1 MATLAB/Simulink model for impedance calculation in dSPACE1104 53

Fig. E.2 dSPACE1104 console to display measurement result 53

\section{LIST OF TABLES}

Table I Compatibility and usability analysis of different ripple voltage sensing IC 36

Table II Battery impedance measurement result 41

Table III Comparison of battery impedance measurement result 42

Table IV Components value of low pass and all pass filter 50 


\begin{abstract}
Battery impedance measurements are directly correlated with the internal thermal rise and lifetime of rechargeable Li-ion batteries. The ac impedance measurement is not only reflects the battery state of health, but also a crucial parameter for a charging control strategy to reduce the internal thermal rise. The battery ac impedance is achieved with a battery charger by injecting ac ripple current and measuring the ac voltage response with the sinusoidal ripple current (SRC) charging technique. The digital signal processor is used to extract the battery ac ripple content and calculate the impedance magnitude and phase angle. However, it has computational burden due to many signal transformation steps, extracting the ac ripple content, creating the virtual $\alpha-\beta$ frame for separating the impedance phase angle, and computational complexity with limited ADC sensing range between 0 to $3 \mathrm{~V}$ at 12-bit resolution.

The battery online impedance measurement using SRC emulator is describes in this thesis. To perform the battery impedance measurement, the hardware implementation of a 16-channel filter sensing board (FSB) is proposed for extracting the battery ac ripple current and voltage response. In addition, impedance calculation algorithm is also developed by dSPACE1104 for calculating the battery impedance magnitude and phase angle. The experiment was performed by charging a 12.8 V, $40 \mathrm{Ah}$ Li-ion battery at $\mathrm{C} / 8$ rate in $\mathrm{CC}$ mode with perturb $\pm 1 \mathrm{~A}_{\mathrm{ac}}$ ripple current, and the battery ac impedance was measured by sweeping the ripple frequency from $20 \mathrm{~Hz}$ to $2 \mathrm{kHz}$.
\end{abstract}

Keywords: SRC emulator, electrochemical impedance spectroscopy, Li-ion battery, Battery ac impedance, Filter sensing board and dSPACE1104 control desk. 


\section{Chapter 1. Introduction}

The motive behind this thesis is given in the first chapter together with a background of Li-ion battery, literature review and statement of thesis goals. Also, a summary of the report layout is presented.

\subsection{Background}

Batteries are considered one of the most common devices for storing electric energy. At present, an energy storing system has been an attractive research field, due to the rapid growth of electrified transportation, and the need to mitigate variability in renewable energy sources. In recent decades, the importance of rechargeable batteries has been increased in modern electrical industry and widely used in various fields of applications [1-2]. It has been used in portable electronics, backup power supplies, hybrid electric vehicles, medical instrumentation, aerospace technologies, telecommunication, industrial manufacturing, and micro grid systems [3-10]. In these diverse applications, a large-scale energy storage capacity, high energy and power density, low cost, and robustness electric battery is required for smooth operation. Since rechargeable batteries come in different chemistry compositions such as, lead-acid, Alkaline, Nickel-Iron, Nickel-cadmium, Lithium cobalt oxide, Lithium-ion, Lithium-ion phosphate, and Lithium sulfur etc, each chemistry composition has its own characteristics, capacity, maximum and minimum voltage, energy density, power, self-discharge rate, number of cycles, and life time etc. The demand market of Li-ion batteries has been increased due to their high efficiency, longer life, high gravimetric, volumetric energy, and power density properties among the different chemistry compositions [11-12].

When a Li-ion battery cell is charged or discharged, the electrochemical process occurs inside the cell and transfers the ion from one electrode to the other electrode through the electrolyte. 
The electrolyte solution acts as a medium to transport the Li-ions and enables an initial concentration of ions for the electrochemical process. The concentration of ions at the electrode's surface and the metallic structure of electrodes are a few among the many factors that can affect the characteristics of a Li-ion cell [13]. The battery dynamic behaviors of the interface are occurred due to polarization and the diffusion effect in their continuous operation. Therefore, the internal impedance of a battery depends on the charge transfer reaction, mass transport in the electrolyte, diffusion of lithium within the active electrode material particles, the change of double-layer capacitor on the active electrode material, and ohmic resistance.

The battery equivalent circuit model is shown in Fig. 1.1 based on the dynamic characteristics of the electrode and electrolyte interface. This circuit model has been considered the battery dynamic characteristics such as diffusion, activation and concentration polarization, double layer capacitance impact, and Warburg impedance [14]. Typically, the ohmic resistance, $R_{o}$ is modeled based on the conductivity of the electrolyte and temperature. The layer between the electrode surface and electrolyte is modeled as a charge transfer resistance, $\mathrm{R}_{\mathrm{CT}}$, and double layer capacitor, $\mathrm{C}_{\mathrm{DL}}$. The concentration polarization effect is also represented by the Warburg impedance, $\mathrm{Z}_{\mathrm{w}}$. The parasitic inductor, $\mathrm{L}_{\mathrm{e}}$, accounts for the battery contact inductance due to external circuit connection.

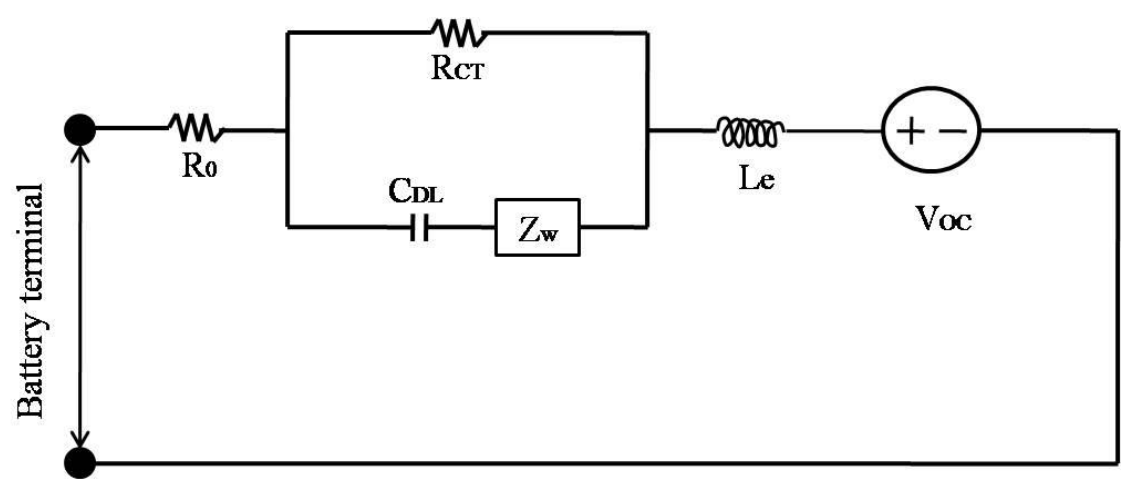

Fig. 1.1 Battery Equivalent circuit model 
The measured ac impedance spectrum of a battery cell over a range of frequencies is shown in Fig.1.2, with the classified sections. Nyquist plot is the common method to represent the impedance of a system in which the negative component is plot against the positive component of the impedance. Since the dominant part in the cell at low frequencies is mainly capacitive, the sign of the imaginary axis is reversed resulting in the capacitive region being in the first quadrant of the plot. The semicircles within the mid-high frequency window depict the charging of double layers capacitive effect on the materials within the electrodes, and the contribution of different resistances. One of the semicircles indicates the rate of the charge transfer reaction. At lower frequencies, the tail is mainly affected by the diffusion within the electrolyte and active electrode materials. The real impedance at the top left most points in the Nyquist plot reveals the ionic and electrical conductivity within the cell.

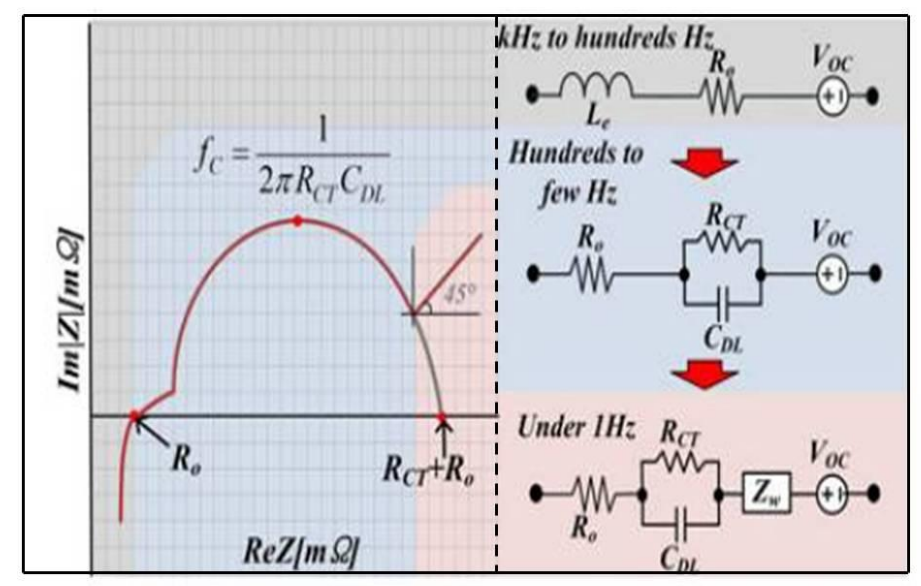

(a)

(b)

Fig. 1.2 (a) Nyquist plot of Li-ion cell and (b) sectionized equivalent circuit [15]

Since the battery internal characteristics have a complex and dynamic behavior, the performance of a secondary battery depends on the internal battery impedance, charging condition, state of charge (SOC), electrochemical properties, and charging current profile. The higher internal impedance will cause more thermal rise of a battery and energy loss. Therefore, it is an important 
to obtain lower battery impedance considering the advanced charging techniques. Many research works have been done aimed to monitor the battery online impedance, increasing the battery performance, and reducing the internal thermal rise of a battery at optimal charging frequency during charging operation.

\subsection{Literature Review}

It has been found many research works related to investigate the battery internal impedance, extend the life time and performance of a battery while reducing the associated losses. Since battery life time depends on the five factors: proper storage, internal temperature rise, battery chemistry, cycling, and maintenance [16]. Among these factors, the storage facilities and temperature impact are the most harmful effects on battery run time. Failure to comply with proper storage and variation of operating temperature reduced the battery expected life time as well as the battery capacity. Each $8^{\circ} \mathrm{C}\left(15^{\circ} \mathrm{F}\right)$ rise in temperature from operating point cuts the run time of a sealed lead acid battery in half [17]. The battery lifetime depends strongly on the internal temperature in high power applications [18]. Decrease of battery capacity means an overall decrease in the driving time of electric vehicles, while the increase in internal impedance causes a reduction in the power handling capability. Therefore, the charging methodology plays a significant influence on the performance and aging life of Li-ion batteries.

Recently, the sinusoidal ripple current (SRC) charging technique has been proposed considering the electrochemical characteristics of a battery. The conventional battery charging techniques typically do not take into account the electrochemical properties of a battery during charging

operation. In SRC charging technique, the ac ripple current is superimposed into dc charging current for analyzing the time varying characteristics of a battery. In this charging method, the 
battery is charged by a constant dc charging current while the frequency dependent ac ripple current imaged the internal ac impedance of a battery. In addition, with dc charging current the battery internal thermal rises due to both mechanical (ohmic) and electrochemical (Faradic) heating, which depends on the ripple frequency and magnitude [19]. The electrochemical resistance is a non-linear dynamic manner due to polarization, diffusion and the double layer capacitive effect. In order to identify the frequency dependent characteristics of a battery, different ripple current frequencies are perturbed into dc charging current in SRC charging technique. Usually, the ripple current frequency is swept from $0.1 \mathrm{~Hz}$ to $1 \mathrm{kHz}$ in a $12.8 \mathrm{~V}, 40$ Ah Li-ion battery for finding the minimum impedance point [20]. Therefore, the impedance parameters of the equivalent circuit of a battery are reflective of electrochemical reactions and transport processes [21]. There are different approaches available to measure the battery internal impedance: dc discharge, ac current injection method, sinusoidal duty perturbation in battery charger, and motor controller excitation method [22-27]. The most direct measurement method is the ac current injection method.

Usually, impedance spectroscopy is a well known measurement technique and widely used in the field of electrochemistry and material sciences to analyze the impedance of an object at various frequencies [28]. Electrochemical impedance spectroscopy (EIS) has been used in many studies to define electrochemical properties of batteries and to understand the characteristics of batteries in alternating current (ac) analysis. There are two electro-analytical techniques to measure the change in electrical impedance at the electrode and electrolyte interface: 1) generates current stimuli of certain frequencies and measures the voltage response (Galvanstatic Mode), and 2) generates voltage stimuli of certain frequencies and measures the current response (Potentiostatic Mode). Usually, the galvanstatic mode is preferred to extract the battery equivalent circuit 
parameters, and investigate the battery cell kinetics by applying the ac impedance measurement technique [29-30]. In SRC charging technique the ac impedance measurement approach has been proposed to find the battery impedance angle and magnitude with respect to ac ripple frequency. Since the battery ac voltage response is the function of the applied ac ripple current. Therefore, in SRC charging technique, the excitation ac ripple current is applied and then the corresponding ac ripple voltage response is measured for calculating the battery ac impedance. The optimal charging frequency is the minimum ac impedance frequency, $f_{z \_ \text {min }}$ at which the impedance value is minimum, $Z_{\min }$. In order to find the optimal ripple frequency the frequency tracker has been developed by the phase locked loop (PLL) for detecting, tracking and locking at optimal frequency [31-32]. This new charging method is used to analyze the variations of battery impedance with respect to ac ripple frequency and magnitude at different state of charge (SOC) level of a battery. The online impedance measurement of a Li-ion battery $(12.8 \mathrm{~V}, 40 \mathrm{Ah})$ has been performed by analyzing the charging voltage and current using digital signal processor (DSP) [20]. The measuring impedance information can be utilized in SRC controller development, ascertained the SOC, determined the state of health $(\mathrm{SOH})$, and found the optimal charging frequency for smart BMS applications.

\subsection{Problem Statement}

The literature review shows that the battery online impedance measurement is an emerging research field for obtaining an optimal charging technique to develop an intelligent battery management system. In SRC charging method, the inner electrochemical characteristics have been considered to obtain the equal ions distribution in a Li-ion battery to improve the charging performance [33]. The SRC charging technique is applied due to 1) analysis the impact of a ac ripple current magnitude and frequency on battery internal characteristics, 2) find the optimal 
ripple current at the minimal impedance point, 3) determine the parameters of loss factors related to temperature and reduction of lithium plating and 4) obtain more frequently updated parameters information in order to better utilization of battery. To implement the SRC charger for a large stack in battery it is expensive and complex than for a signal battery charger. In term of battery online impedance measurement, the ac ripple current perturbed into dc charging current and measured the corresponding ac ripple voltage response. The online impedance measurement has been performed using DSP and developed the algorithm for calculating the impedance magnitude and phase angle in SRC charging technique [20]. However, the applied SRC charging approach has a computational burden due to many signal transformation processes, such as analyzing charging current and voltage, filtering the dc offset and extracting the battery ac ripple information, creating the virtual $\alpha-\beta$ signals of ripple voltage and current, $d$ q transformation of ac ripple signals for separating the impedance angle, and computational steps for impedance calculation using ripple power method. In addition, the DSP has a limited ADC sensing range from 0 to $3 \mathrm{~V}$ at 12-bit resolution and variation of phase angle delay of sensing ripple voltage and current with respect to sweep the ac ripple frequency.

\subsection{Proposed Solution}

Typically, an emulator is used to avoid the design surprise and to validate of a new concept and control strategy before applying in a real time system. Increasing the interest in SRC charging systems will motivate to develop a simple way to validate the SRC charging method before implementing in a physical system. This thesis proposes the SRC emulator without a ripple current controller for charging the battery in SRC charging technique and measuring the online battery impedance. Since the internal behavior of batteries is dynamic, it is beneficial to use the SRC emulator to validate the SRC performance before to integrate on a battery charger. 
Therefore, this work explores the development of SRC signal generation, extraction of the battery ac ripple content using a filter sensing board (FSB), and development of the dSPACE1104 impedance calculation algorithm. The proposed hardware FSB reduces the signal transformation processes and computational steps for measuring the battery online impedance in SRC charging techniques.

\subsection{Thesis Outline}

The thesis is organized into 6 chapters which are as follows:

Chapter 1. Introduction

Background, literature review, problem identification, proposed solution, and the thesis writing structure.

Chapter 2. Sinusoidal Ripple Current Emulator

Introduction of emulator, configuration of SRC emulator, AC ripple current charging profile, sinusoidal ripple current generator: (1) AC source perturbation, and (2) Programmable load perturbation, battery ripple voltage and current extraction and ac impedance extraction.

Chapter 3. Design and Hardware Implementation of Filter Sensing Board

Introduction, battery current and voltage sensing, decoder/encoder, filter circuit design, pass band filter, all pass filter and PSIM simulation.

Chapter 4. AC Impedance Calculation of a Battery

Battery equivalent ac impedance, impedance extracting method, dSPACE1104 Control Desk and impedance calculation algorithm. 
Chapter 5. Experimental Results

General overview, experimental test result, signal measurement, ac ripple extraction and impedance measurement results.

Chapter 6. Conclusion and Further work.

Appendix A. Publications

Appendix B. References

Appendix C. Filter Circuit Design

Appendix D. Hardware Design and Implementation

Appendix E. dSPACE1104 Impedance Calculation 


\section{Chapter 2. Sinusoidal Ripple Current Emulator}

The general theory behind the SRC emulator proposal, the approach to generate sinusoidal ripple current for measuring battery ac impedance and a brief explanation of ac impedance extractions are presented in this chapter.

\subsection{Introduction}

The purpose of the emulation approach in the electric drive and electronic applications is to design a system with hardware devices, which can reproduce the physical system functioning in real time with high precision. This system is called emulator. Typically, emulator is used to validate of a new concept and control strategy. In order to avoid the design complexity an emulator can be used to validate a control strategy before installing in a real time system. Recently, emulators are used in renewable energy conversion systems. PV emulators have the capability to imitate the behavior of a variety of PV panels under different environmental conditions [34-36]. In wind energy conversation systems, the main challenge is the non linear behavior of wind turbine and the erratic nature of wind. To overcome these difficulties, wind turbine emulators have developed and validated the response of real hardware using advanced perturbation methods [37]. It has also been designed to facilitate tests on wind energy systems under several wind speed conditions for feasibility and performance analysis of a wind emulator [38-40]. The SRC emulation is a strategy to produce the ac ripple current perturbation into dc charging current and streamline the testing process, ensuring considerable savings in designed time and cost before implementing in an actual battery charger. Therefore, this thesis describes the development procedure of SRC emulator in detail for charging the electric battery and verifying the concept of SRC charging technique. 


\subsection{Configuration of SRC Emulator}

The proposed SRC emulator is shown in Fig. 2.1. It has three sections: 1) the SRC generator for charging the battery in SRC charging method, 2) the process of extracting the battery ac ripple voltage and ac ripple current by filtering the dc offset using a filter sensing board (FSB), and 3) impedance magnitude and phase calculation performed by dSPACE1104. The FSB also provide the $\alpha-\beta$ signals of the battery ac ripple content for separating the impedance angle in $\mathrm{d}-\mathrm{q}$ method.

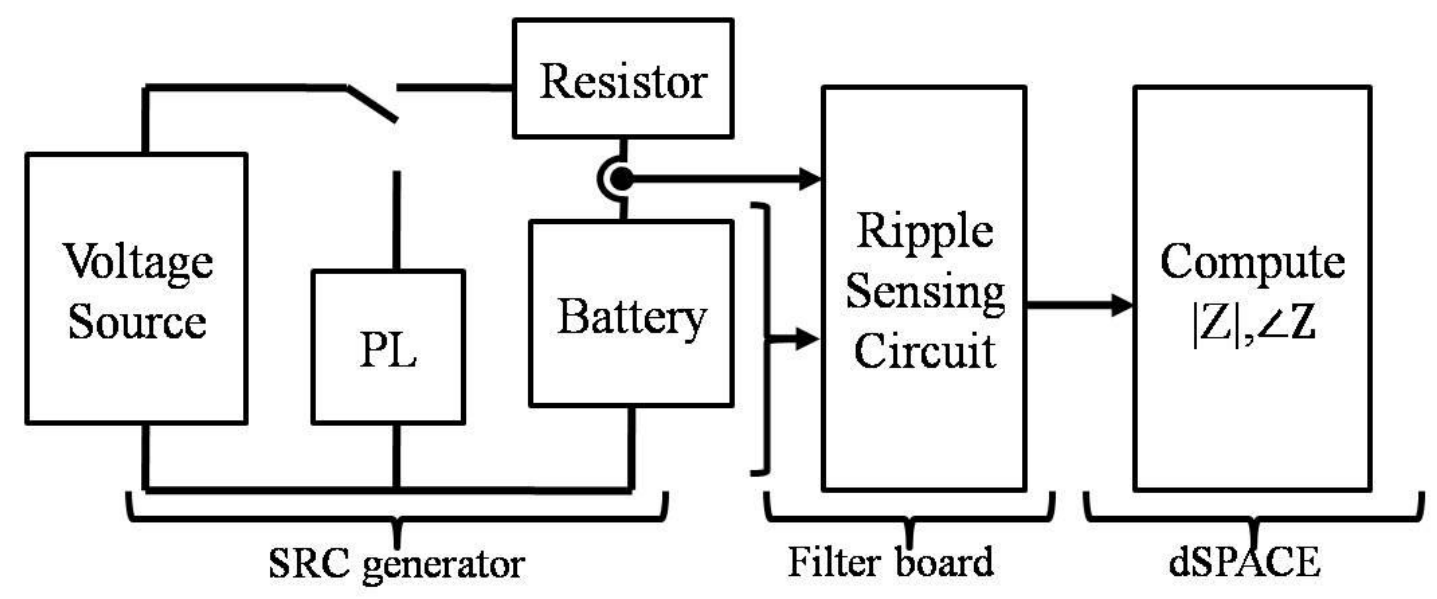

Fig.2.1 Configuration diagram of SRC emulator

\subsection{Sinusoidal Ripple Current Profile:}

The sinusoidal ripple current is superposed into dc charging current in SRC charging technique. The charging current profile of this new battery charging method is shown in Fig.2.2.

$I_{-}$Total $=I_{d c}+I_{a c}=I_{d c}+I_{m} * \sin (2 \pi f t)$

Where, $\mathrm{I}_{\text {Total }}$ is the total battery current in SRC method, $\mathrm{I}_{\mathrm{dc}}$ is the constant de charging current, $\mathrm{I}_{\mathrm{ac}}$ is the peak-to-peak ac ripple current, $\mathrm{I}_{\mathrm{m}}$ is the maximum value of ac ripple current, and $\mathrm{f}$ is the ripple current frequency. 


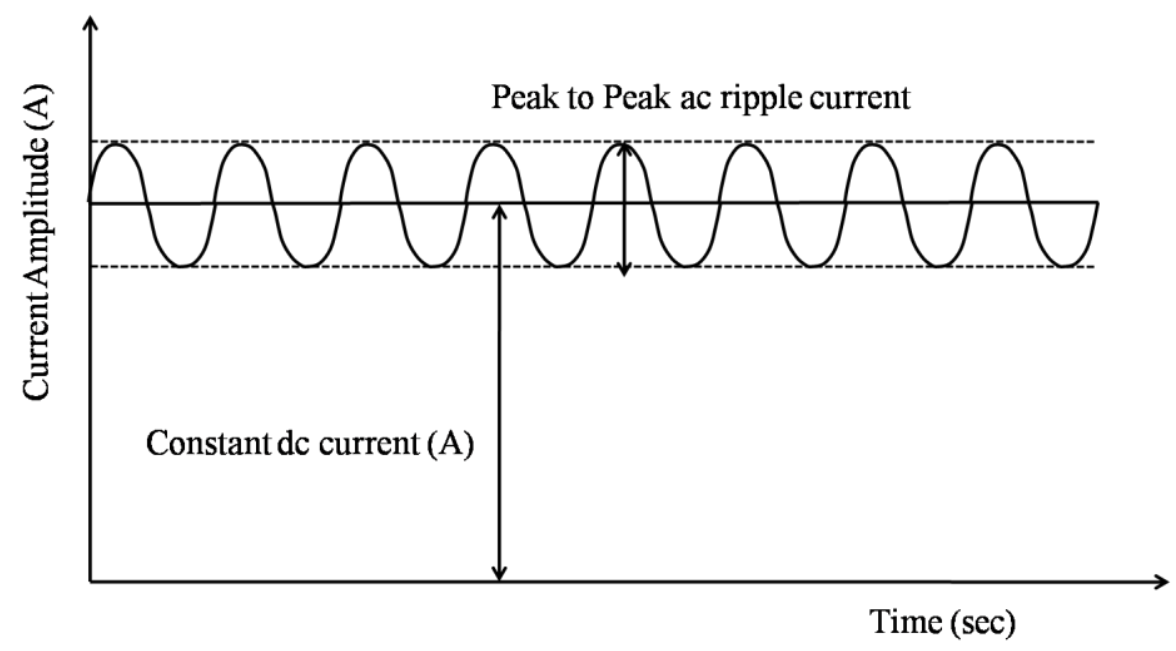

Fig.2.2 Sinusoidal ripple charging current

\subsection{Sinusoidal Ripple Current Generator}

An emulator is to imitate the original behavior of the actual system without the real test environment. A sinusoidal ripple current emulator superimposes various ac ripple current frequencies into dc charging current for producing SRC without an ac ripple current charger. In this thesis, a possible way to develop the SRC generator using physical load and power sources is presented. Basically, the SRC generator can be designed in two ways: 1) ac source perturbation, and 2) programmable load perturbation methods for charging the battery using a SRC emulator.

\subsubsection{AC Source Perturbation}

The proposed circuit diagram of the SRC generator using ac source perturbation is shown in Fig. 2.3 (a). It is composed of both ac and dc power sources. The AMX3120 ac power source is used to perturb the ac ripple current at different frequencies into dc charging current supplied by an ABC 150 dc power source. In this method, the ac and de voltage sources both operate in constant 
voltage supply mode and are connected in series with an external resistive load, R, and a battery. The battery internal resistance, $\mathrm{R}_{0}$, is $15 \mathrm{~m} \Omega$ [41]. The constant dc charging current is defined by the external resistive load, R. From (2.2), the constant dc charging current can be produced at the expected charging level by programming the dc voltage in $\mathrm{ABC} 150$, while the ac ripple current is produced using the AMX3120 ac programmable source at specific frequency and magnitude. The ac source has the capability to generate up to $32 \mathrm{~A}_{\mathrm{rms}}$ output current off of a single phase from a 3- $\Phi$ bus and with an output voltage of $135 \mathrm{~V}_{\mathrm{ac} \text { 1-n }}$ in direct coupling mode, and the ac ripple frequency sweeping range is from $20 \mathrm{~Hz}$ to above $2.5 \mathrm{kHz}$ [42].

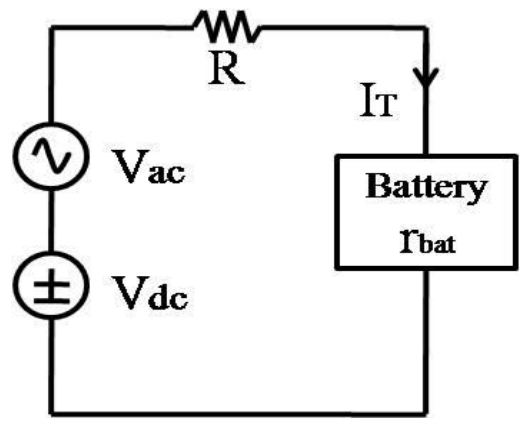

(a)

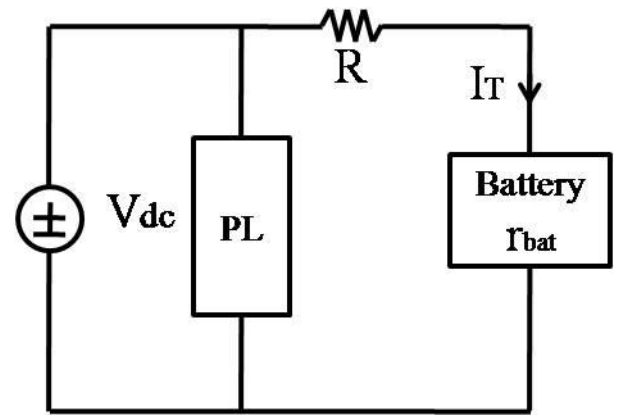

(b)

Fig. 2.3 Circuit diagram for ac ripple current generator using (a) ac source perturbation (b) ac load perturbation

$\mathrm{I}_{\mathrm{T}}=\mathrm{I}_{\mathrm{dc}}+\mathrm{I}_{\mathrm{ac}}=\frac{V_{d c}-V_{b a t}}{R+R_{0}}+\frac{V_{a c}}{R+R_{0}} \cong \frac{\Delta V}{R}+\frac{V_{a c}}{R}$

$\mathrm{I}_{\mathrm{T}}=\mathrm{I}_{\mathrm{dc}}+\mathrm{I}_{\mathrm{ac}}=\frac{V_{d c}-V_{b a t}}{R+R_{0}}+\mathrm{I}_{\mathrm{ac}}$

Where, $I_{T}$ is the total current, $I_{d c}$ is the dc charging current, $I_{a c}$ is the ac ripple current perturbation, $R$ is the series resistive load, $V_{d c}$ is the dc supply voltage, $V_{\text {bat }}$ is the battery terminal voltage, $\mathrm{R}_{0}$ is the battery ohmic resistance and, $\mathrm{V}_{\mathrm{ac}}$ is the ac voltage, and $\mathrm{V}_{\mathrm{pp}}$ is voltage drop across the resistor, $\mathrm{R}$. 


\subsubsection{Programmable Load Perturbation}

The circuit diagram of the SRC generator using programmable load perturbation is shown in Fig. 2.3(b). In the programmable load perturbation technique the ac ripple current is superimposed on the dc charging current using Chroma 63803 ac/dc programmable load (PL). The Chroma 63800 dc load can operate in four load modes: constant current, constant resistance, constant voltage and constant power. A special de rectified mode is included to mimic the loading behavior of the distributed load. In the proposed SRC emulator the PL is programmed in dc rectified mode for superimposing the ac ripple current. With this configuration, the PL is connected in parallel with the dc current source and the battery is connected with the source through $\mathrm{R}$. The resistive load regulates the dc charging current depending on the voltage drop across it and the PL superimpose ac ripple current in (2.3). The PL impacts on the dc charging current and producing the ac ripple current on top of the dc current. The dc charging currents magnitude can be controlled by the dc power supply, ABC150. The Chroma 63803 PL can sink up to $36 \mathrm{~A}_{\text {rms }}$ current, handle $3.6 \mathrm{~kW}$, and operate from $40 \mathrm{~Hz}$ to $400 \mathrm{~Hz}$ [43].

\subsection{Battery ac Ripple Extraction}

In order to extract the battery ac ripple voltage and current signal, the first step is to measure the battery voltage and current. This thesis proposed and hardware implemented a 16-channel filter sensing board (FSB) using analog circuitry for extracting the ac ripple content of a battery to calculate the ac impedance. Therefore, the voltage and current sensors are used to measure the down-scaled battery voltage and current for the low power op-amp circuitry. The second step is to filter the dc offset voltage and extract the battery ac ripple content. To perform these the lowpass filter is used which leaves the dc components and extracts the ac signals. The designing 
procedure and working principle of FSB is described in detail in chapter 3. This FSB has two important properties: 1) extracting the battery ac ripple information, and 2) creating the $\alpha$-signal and $\beta$-signal of the battery ripple voltage and current. These $\alpha-\beta$ signals are used in the next step for developing an impedance calculation algorithm in dSPACE1104 to extract the battery ac impedance. In order to calculate the impedance magnitude, and phase angle the d-q transformation technique is used in the proposed method.

\section{6 dSPACE1104 Impedance Calculation}

The impedance calculation process is performed by dSPACE1104 using the battery ac ripple voltage response due to ac ripple current excitation in SRC charging method. In order to separate the impedance angle the stationary $\alpha-\beta$ signals of battery ripple voltage and current is transformed into a d-q rotating frame signals. The battery impedance magnitude and phase angle is calculated using dSPACE1104 calculation. The detailed impedance calculation algorithm is described in chapter 5 . 


\section{Chapter 3. Design and Hardware Implementation of Filter Sensing Board}

The hardware design and implementation of the 16-channel filter circuit board for extracting the ac ripple content and creating the $\alpha-\beta$ frame signal are discussed in detail in this chapter.

\subsection{Filter Sensing Board (FSB)}

In SRC charging technique the battery is charged by dc current and ac ripple current superimposed on dc charging current. Therefore, the battery terminal dc voltage depends on dc charging current while the ac ripple voltage response arises due to ac ripple current perturbation. Usually, the maximum allowable peak to peak ac ripple current depends on the battery charging current rate (C-rate). Because the ac ripple current is lower than the dc charging current, and the battery internal dc resistance is in the $\mathrm{m} \Omega$ range, therefore the peak-to-peak ac ripple voltage response of a Li-ion battery is also low, typically in $\mathrm{mV}$ range. In order to extract the battery ac ripple current and voltage the hardware FSB has been proposed [44]. The proposed FSB is shown in Fig. 3.1. It consists of the battery voltage and current sensing section, decoder and encoder, and filter channels. The decoder selects the specific channel among 16-channels corresponding to the ac ripple frequency and sends to the filter section for removing the dc offset and extracting the ac ripple information from a battery. In SRC charging technique the ac ripple frequency is swept from $0.1 \mathrm{~Hz}$ to $1 \mathrm{kHz}$ range for obtaining the minimum battery impedance at optimal charging point [20]. The proposed 16-channels filter circuit provides the flexibility to extract the battery ac ripple information corresponding to 16 different frequencies within a certain range. The second order Butterworth low pass filter and the differential amplifier are used to produce the pass band signal corresponding to the ac ripple frequency. The output of the pass band filter becomes the $\alpha$-axis signal while the all pass filter produces the $\beta$-axis signal. The RC low pass filter removes the high frequency noise and the inverting amplifier increases the signal 
strength. The unity gain all pass filter passes all frequencies and produces a $90^{\circ}$ phase delay at the pass band frequency. The following few sections are describes the battery ac ripple voltage and current extraction procedure, briefly.

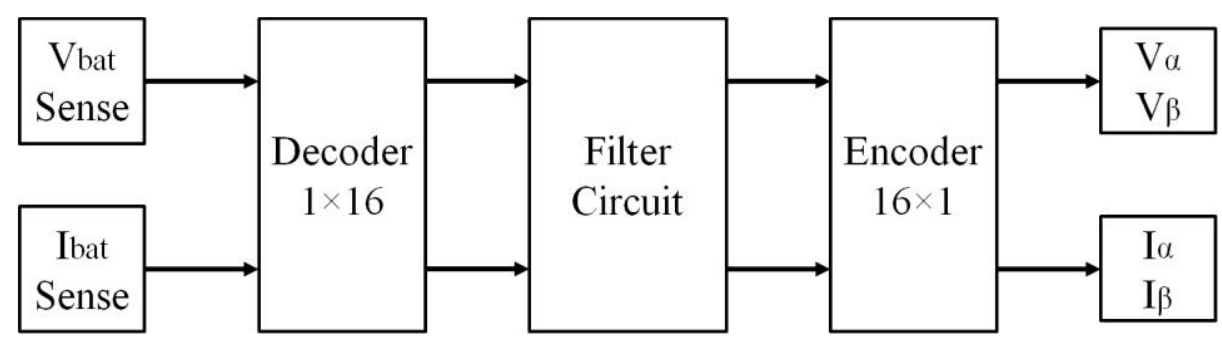

Fig. 3.1 Signal processing of the $\alpha-\beta$ frame of ripple voltage and current

\subsection{Battery Current and Voltage Sensing}

\subsubsection{Current Measurement Circuit}

The ACS712 current sensor shown in Fig. 3.2, provides the voltage response corresponding to the input line current. It also can be used to protect the battery from over current fault. This device has a precise, low-offset, linear Hall circuit that generates a magnetic field and converts into a proportional voltage corresponding to the applied input line current. The output current sensitivity is $66 \mathrm{mV}$ to $185 \mathrm{mV}$ per ampere depending on the IC package. It has the capability with high precision to measure both ac and dc current. This device package allows for easy implementation by the customer and use for both AC and DC current sensing in industrial, commercial, and communications systems. Typical applications are including motor control, load detection and management, switch mode power supplies, and over-current fault protection etc. 


\section{Designing consideration:}

- Supply voltage-5V, $1.5 \%$ tolerance and $\pm 30 \mathrm{~A}$

- Output : zero current : Vcc $\times 0.5=2.5 \mathrm{~V}$

- Rise time : 3.5us @ $C_{\text {out }}=$ open, $C_{\text {out }}=10 \mathrm{nF}$

- Bandwidth design: $R_{F}=1.7 \mathrm{k} \Omega$ (Internal resistance), $C_{F}=1 \mathrm{nF} \rightarrow f_{c}=93 \mathrm{kHz}, \tau=1.7 \mathrm{us}$.

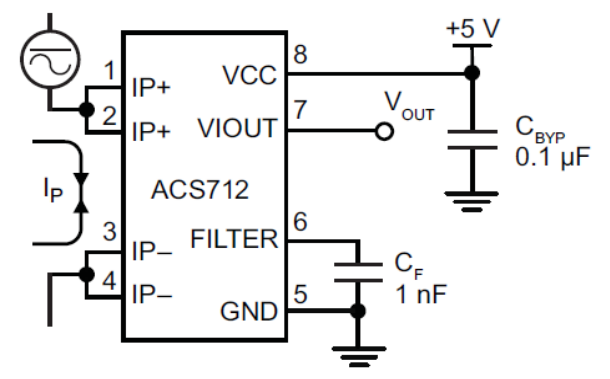

Fig. 3.2 Current sensing circuit [45]

\subsubsection{Voltage Measurement Circuit}

The voltage sensor is used to sense the down scaled battery voltage for over voltage protection as well as measuring the terminal voltage across the battery terminal. Usually, the isolation differential amplifier is used to measure the input voltage [46]. In SRC charging technique the voltage across the battery terminals contain both the dc and ac ripple voltage. Usually, the ac ripple voltage response is very low due to low internal impedance of a battery. Therefore, a higher measuring accuracy based sensing IC is required for sensing the battery ac ripple voltage. The AD8276 voltage sensor IC is shown in Fig. 3.3. It is a general purpose, unity gain difference amplifier that provides both the $\mathrm{dc}$ and ac voltage measurement and monitoring functionalities. It has the capability to measure $\mathrm{mV}$ range ac ripple voltage with higher measurement accuracy. In the next chapter, the investigation of sensing capability and usability of different voltage sensing ICs are described with ac ripple measurement results.

\section{Designing consideration:}

- Supply Voltage range $\pm 2 \mathrm{~V}$ to $\pm 18 \mathrm{~V}$

- Input voltage range $\pm 30 \mathrm{~V}$ with $0.1 \%$ gain error 
- Bandwidth, $550 \mathrm{kHz}$

- Low offset error, $\pm 2 \mathrm{uV} /{ }^{\circ} \mathrm{C}$

- Response time, $\tau=15$ us

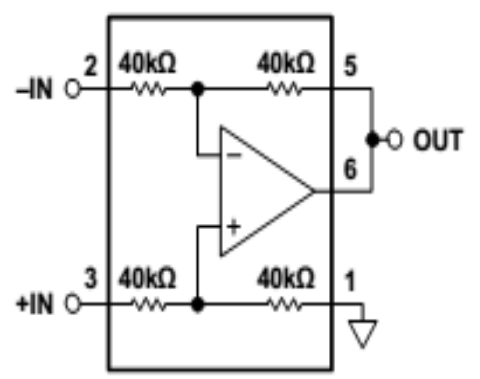

Fig.3.3 Voltage sensing circuit [47]

\subsection{Decoder and Encoder}

The decoder section selects the filter channel corresponding to the ac ripple frequency of the battery voltage and current signal. The filter circuit removes the dc offset and creates the $\alpha-\beta$ signal of the battery ac ripple voltage and current for performing the ac impedance calculation in dSPACE1104. The output of the analog filter circuits is encoded and sent to dSPACE1104 interface for calculating the impedance magnitude and phase angle. The MC1407B, analog demultiplexer, is used in FSB for decoding and encoding the analog signal. It is a digitally controlled analog switch, featuring low ON resistance and very low leakage current. The channel is selected by turning on the appropriate analog switch while controlling the 4-bit binary control inputs A, B, C, and D. The functional diagram of MC1407B is shown in Fig. 3.4.

\section{Designing consideration}

- 16-channel multiplexer/demultiplexer

- Supply voltage: $-0.5 \mathrm{~V}$ to $18 \mathrm{~V}$

- Input voltage: -0.5 to $\mathrm{VDD}+0.5$

- Bandwidth : $15 \mathrm{MHz}$, propagation delay

- Rise times : $\mathrm{R}_{\mathrm{L}}=200 \mathrm{k} \Omega, 90 \mathrm{~ns}$,

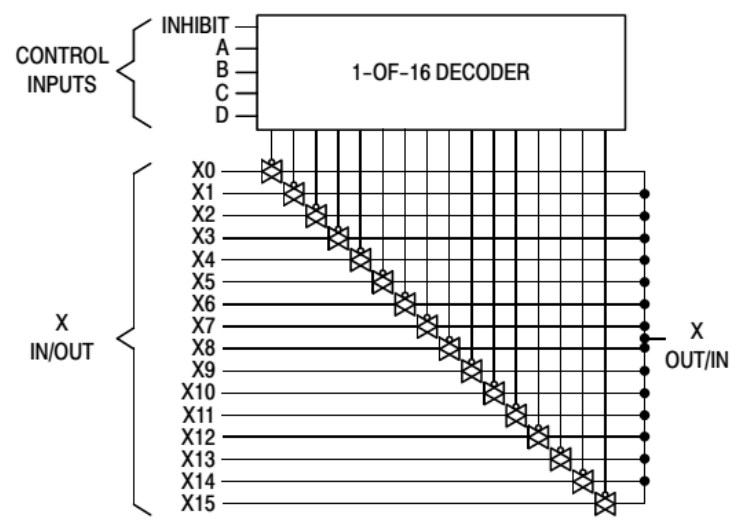

$$
\mathrm{R}_{\mathrm{L}}=1 \mathrm{k} \Omega, 50 \mathrm{~ns}
$$

Fig. 3.4 Functional diagram of MC1407B [48] 


\subsection{Filter Circuit Channel}

In power systems, Butterworth passive filters are usually preferred due to their simplicity and optimal flat behavior in the pass band. Its attenuation only decreases slowly after the cut-off frequency but it can be increased by using higher orders. The suitable filter order must be considered in circuit designing for removing the dc offset successfully. The filter circuit consists of a second order Butterworth low pass filter, pass band filter, R-C low pass filter, inverting amplifier, and all pass filter are shown in Fig. 3.5.

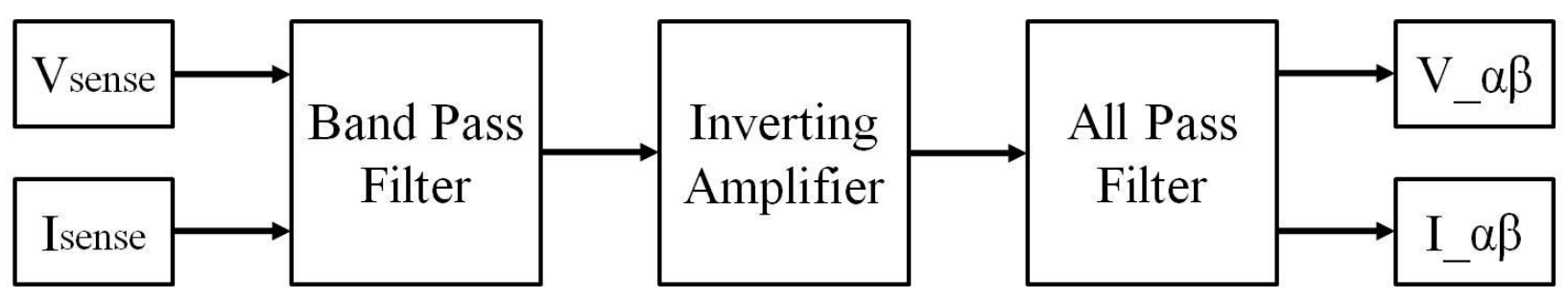

Fig. 3.5 Block diagram of filter circuit for creating $\alpha-\beta$ frame

\subsubsection{Pass Band Filter}

The pass band filter is shown in Fig. 3.6. It is designed for extracting the pass band ac ripple current and voltage signal from a battery during SRC charging condition. The second order Sallen Key topology is used to implement the second order Butterworth active low pass filter. It is a degenerate form of a voltage controlled voltage source filter topology for implementing a 2 pole low pass band filter. The transfer function, $H_{-L P F}(s)$, of the low pass filter circuit is given in (3.1). The output of the low pass filter is subtracted from the input signal by a differential amplifier for removing the dc component (3.3). The RC low pass filter eliminates the high frequency switching noise. The cutoff frequency, $\mathrm{f}_{\mathrm{c} \_b a n d p a s s}$, of the band pass filter is (3.4); 
$\mathrm{H}_{-} \mathrm{LPF}(\mathrm{s})=\frac{V_{o}(s)}{V_{\text {in }}(s)}=\frac{1}{1+\left(C_{2} *\left(R_{1}+R_{2}\right)\right) * S+R_{1} * R_{2} * C_{1} * C_{2} * S^{2}}$

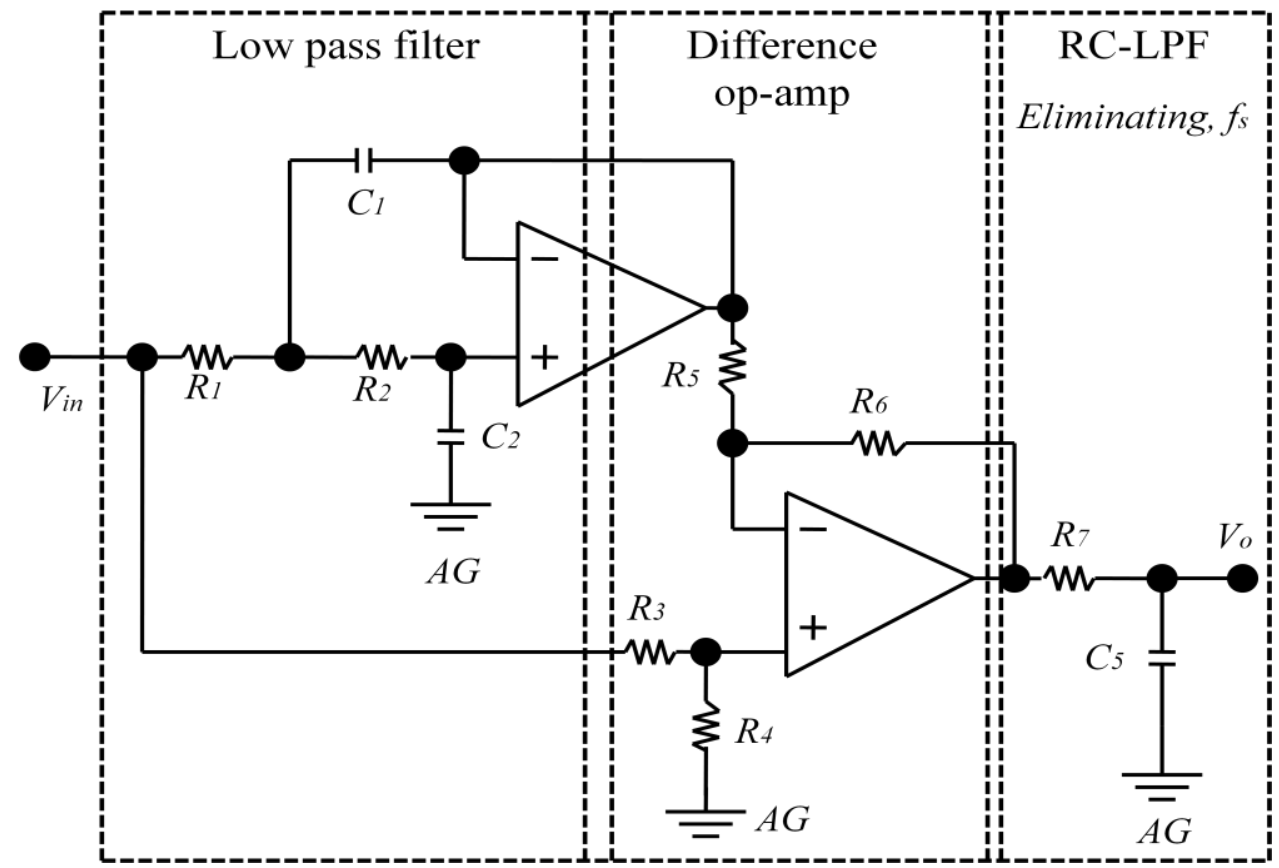

Fig.3.6 Circuit diagram of band pass filter

\section{$\underline{\text { Designing Consideration }}$}

- Two pole low pass filter

- Unity gain, Butterworth response - the flattest response in band

- Cut off frequency, $R_{1}=R_{2}, C_{1}=2 C_{2}, \mathrm{f}_{\mathrm{c}}=\frac{\sqrt{2}}{4 \pi R_{1} C_{2}}$.

- $\quad$ Response time, $\tau=R_{1} \times C_{2}$, Frequency range : $0.01 \sim 2 \mathrm{kHz}$

-Difference amplifier:

- Gain : $1, R_{3}=R_{5}=10 \mathrm{k} \Omega, R_{6}=R_{4}=10 \mathrm{k} \Omega$

- $\quad$ Output equation, $\frac{R_{5}}{R_{6}}=\frac{R_{3}}{R_{4}}, V_{o}=\frac{R_{4}}{R_{3}}\left(V_{i n}-V_{L P F}\right)$ 
- RC Low Pass filter:

- Maximum ripple frequency : $2 \mathrm{kHz} \rightarrow f_{c}=20 \mathrm{kHz} @ 3 \mathrm{~dB}$

- Cut off frequency, $f_{c}=\frac{1}{2 \pi R_{7} C_{5}}=100 \mathrm{kHz}, R_{7} C_{5}=\frac{1}{2 \pi \times 100 k}=1.6 \mathrm{us}$

- $\quad$ ircuit parameter selection, $C_{3}=796 \mathrm{pF} \rightarrow R_{7}=2 \mathrm{k} \Omega$,

\subsubsection{All Pass Filter}

An all pass filter is an active filter circuit that leaves the amplitude of the signal intact but introduces a phase shift. The purpose of this filter is to add phase delay to the response of the circuit. The amplitude gain of an all pass filter is unity for all frequencies while the phase shift is a function of frequency. The phase response changes from $0^{\circ}$ to $360^{\circ}$ (for a 2 -pole filter) as the frequency is swept from 0 to infinity. The unity gain all pass filter produces a $90^{\circ}$ phase delay at the pass band frequency. The output of the all pass filter presents the $\beta$-axis with respect to the input signal, which represents the $\alpha$-axis signal. The analog circuit diagram of an all pass filter is shown in Fig. 3.7. The transfer function of an all pass filter is -

$\mathrm{H} \_\mathrm{APF}(\mathrm{s})=\frac{S^{2}-\left(\frac{\omega_{o}}{Q}\right) S+\omega^{2}}{S^{2}+\left(\frac{\omega_{o}}{Q}\right) S+\omega^{2}}$

\section{Designing Consideration:}

- Inverting amplifier gain, Gain $=-\frac{R_{2}}{R_{1}}$

- Parameter value, for $f_{c}=200 \mathrm{~Hz}, \mathrm{R}=10 \mathrm{k} \Omega, \mathrm{C}=80 \mathrm{nF}$

- Cutoff frequency, $f_{c}=\frac{1}{2 \pi R_{3} C_{4}}$ 
- $\quad$ Output voltage, $V_{o}=\frac{R_{5}}{R_{3}} V_{i n}$, where, $R_{3}=R_{4}=R_{5}$

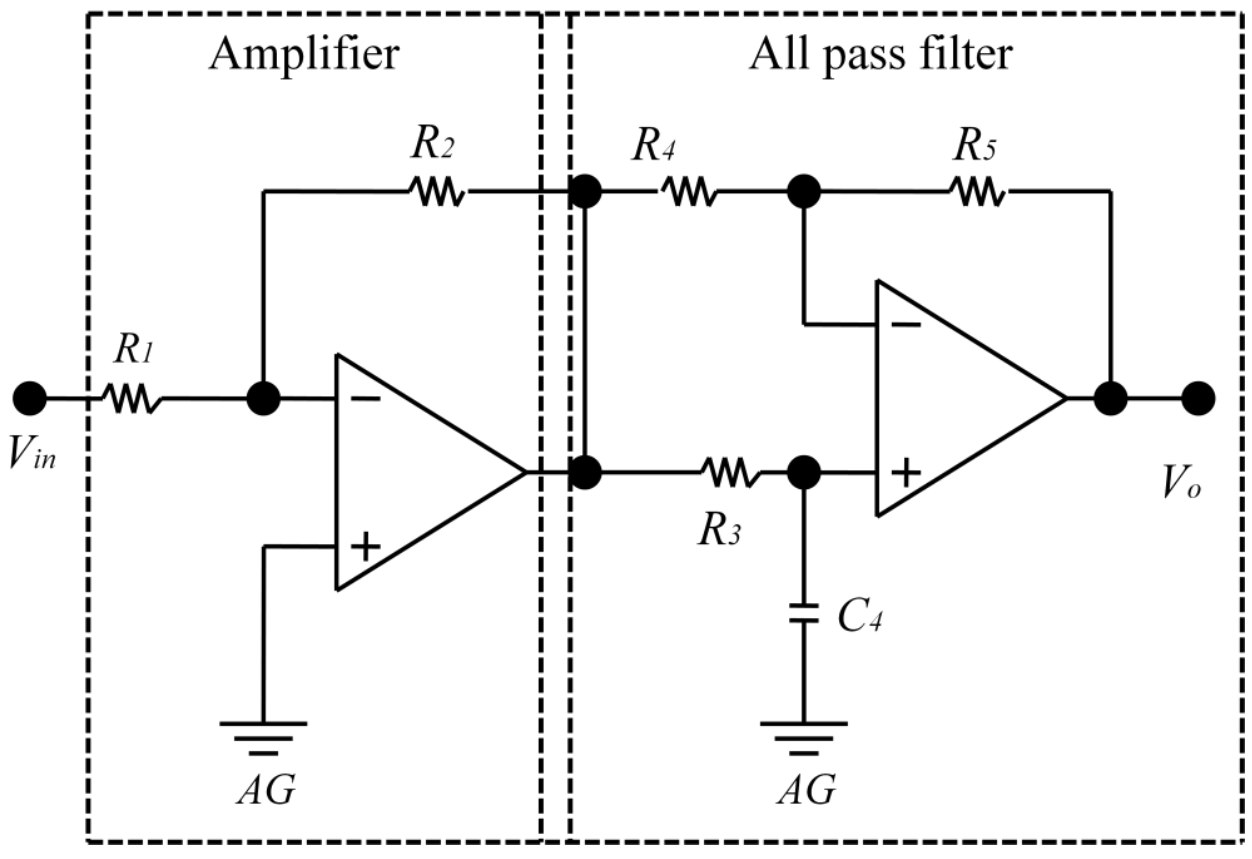

Fig.3.7 Amplifier and all pass filter circuit

\subsection{PSIM Circuit Simulation}

\subsubsection{Simulation circuit model}

The designing considerations of the filter circuit was verified by the PSIM electronic circuit simulation package before implementing the hardware circuit board. The PSIM simulation model is shown in Fig. 3.8. Initially, the 16-channel filter circuits are designed at different frequencies linearly divided from $60 \mathrm{~Hz}$ to $1.0 \mathrm{kHz}$ frequency range. The designing value of the components for the low pass and all pass filter circuits are shown in appendix $\mathrm{C}$ along with the corresponding channel frequencies. The unit of all resistors and capacitors are in $\mathrm{k} \Omega$ and in $\mathrm{uF}$, respectively. 


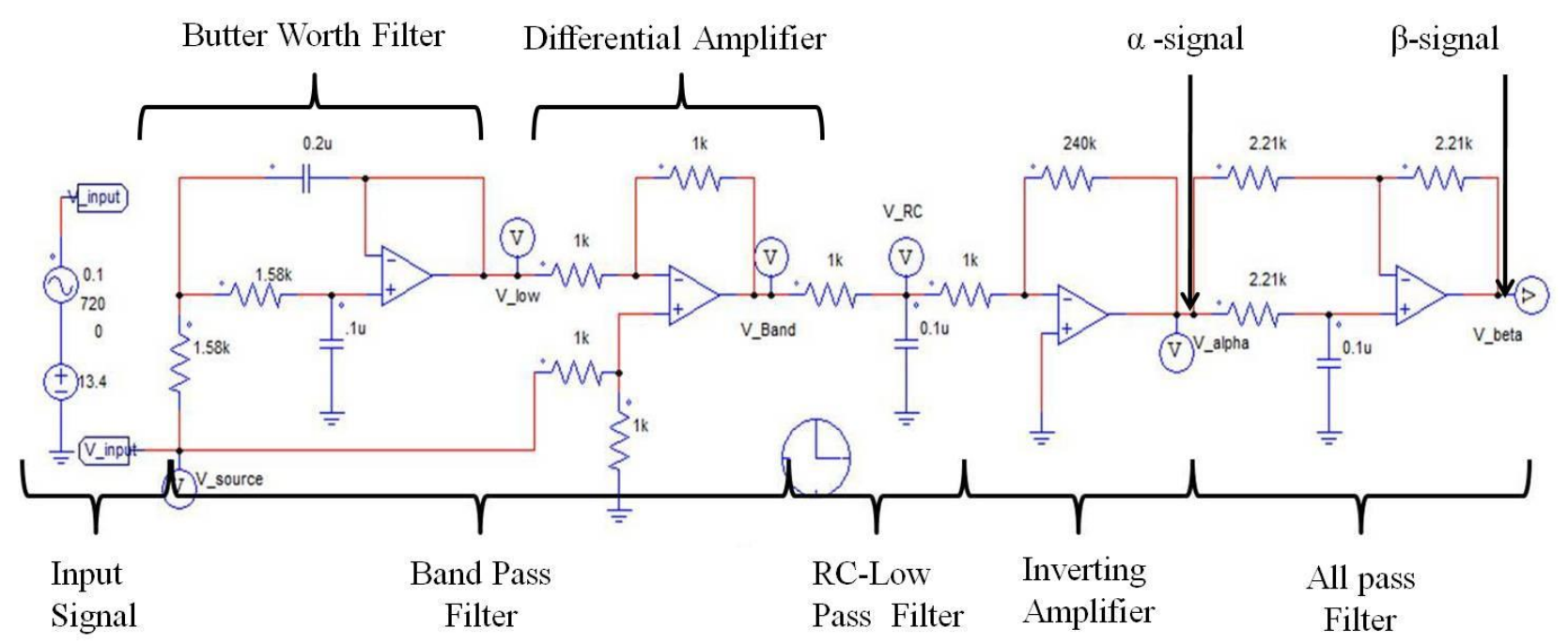

Fig. 3.8 PSIM simulation model of filter circuit for extracting ac ripple content

\subsubsection{Simulation Result}

The PSIM simulation result of the filter circuit is shown in Fig.3.9. The simulation is carried by $2.5 \mathrm{~V}$ dc offset with $2 \mathrm{~V}$ ac signal at $720 \mathrm{~Hz}$ superimposed on the top of the dc offset. In Fig. 3.9(a), the green trace indicates the input signal while the blue and red traces are represent the output of the low pass filter and difference amplifier. The difference amplifier subtracts the output of the low pass filter from the input signal, which removed the dc offset successfully. The RC-low pass filter circuit is designed for eliminating the $100 \mathrm{kHz}$ switching noise. The signal amplifier is used for increasing the signal magnitude in order to become compatible with the dSPACE1104 interface. Fig. 3.9 (b) shows the $\alpha-\beta$ signal, the blue and red trace are indicates the output of pass band signal and all pass filter circuit, respectively. The all pass filter produces an exact $90^{\circ}$ phase delay at $720 \mathrm{~Hz}$ which represents the $\beta$-axis signal. 

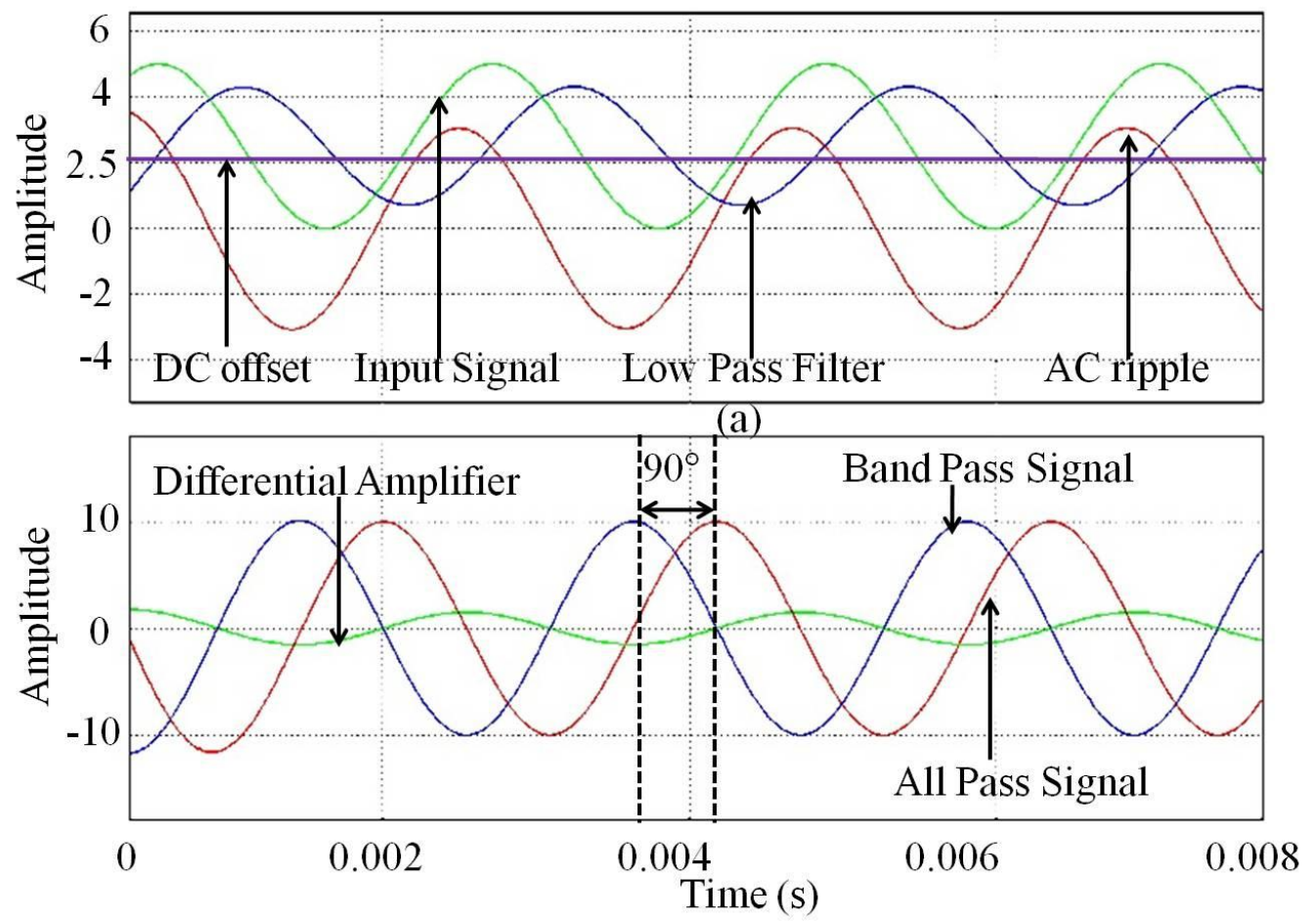

(b)

Fig.3.9 PSIM simulation result (a) low pass filter (b) band pass and all pass filter 


\section{Chapter 4. Battery AC Impedance Calculation}

Introduction of ac impedance extraction, dSPACE1104 control desk, and developing the impedance extraction algorithm using dSPACE1104 is discussed in detail in this chapter.

\subsection{Battery Equivalent AC Impedance}

According to battery electrochemical view, battery cell impedance is a complex quantity that can be measured by a commercial frequency response analyzer. It is defined as the ratio of the cell potential and the cell current, which represents the dynamic behavior of the cell caused by an ac excitation of small current. The measured ac impedance is a frequency dependent complex number. The impedance magnitude is the ratio of $\mathrm{V}_{\max }$ and $\mathrm{I}_{\max }$ while the impedance angle is the difference between voltage and current angles in (4.1).

Battery ac Impedance, $\mathrm{Z}_{(\mathrm{f})}=\frac{V_{\max }}{I_{\max }} e^{j \varphi}$

where, $\varphi=\left(\varphi_{v}-\varphi_{i}\right)$

Typically, the battery equivalent impedance can be expressed as follows according to Fig.1.1.

$Z(s)=Z_{L e}+R_{0}+R_{C T} \| C_{D L}+Z_{w}$

Usually, the Warburg impedance is neglected for frequency range above $1 \mathrm{~Hz}$.

$Z(s)=j \omega L_{e}+R_{0}+\frac{1}{j \omega * C_{D L}+\frac{1}{R_{C T}}}$

Putting $s=j \omega$ in equation (4.4) and separating the real and imaginary parts-

$Z(\omega)=R_{0}+\frac{\frac{R_{C T}}{\left(\omega * C_{D L}\right)^{2}}}{R_{C T}^{2}+\left(\frac{1}{\omega * C_{D L}}\right)^{2}}+\mathrm{j}\left(\omega * L_{e}-\frac{\frac{R_{C T}}{\left(\omega * C_{D L}\right)^{2}}}{R_{C T}^{2}+\left(\frac{1}{\omega * C_{D L}}\right)^{2}}\right)$ 
The frequency, $f_{Z, \min }$, where the magnitude of the ac impedance is minimized. It can be found by differentiating $\left|Z_{\omega}\right|^{2}$ with respect to $\omega$ and then solving for $\frac{d|Z(\omega)|^{2}}{d \omega}=0$. This frequency can be expressed as (4.5) and the corresponding magnitude of the impedance is represented as (4.6).

$f_{Z, \min }=\frac{1}{2 * \pi * R_{C T} * C_{D L}} \sqrt{ }(\mathrm{k}-1)$

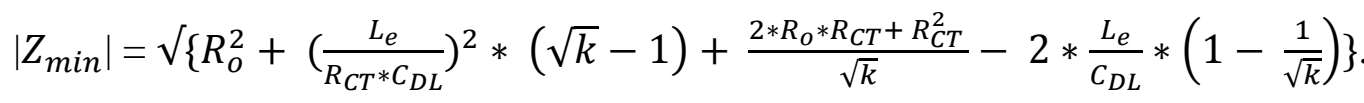

where, $k=\frac{\sqrt{ }\left(2 * R_{O} * R_{C T}^{3} * C_{D L}^{2}+2 * L_{e} * R_{C T}^{2} * C_{D L}+R_{C T}^{4} * C_{D L}^{2}\right)}{L_{e}}$

\subsection{AC Impedance Extracting Method}

In ac impedance technique, the impedance value and phase angle can be done by injecting either ac current or ac voltage and measuring the corresponding ac response. This is because the ac technique is a very strong approach and widely used for extracting ac impedance. In this thesis, the ac impedance measurement technique is used for measuring the battery online impedance using SRC charging technique. Usually, the stationary coordinate $\alpha-\beta$ frame and the rotating coordinate d-q frame are used in a three phase system. Recently, this approach has been applied to separate the impedance magnitude and angle in a single phase battery impedance calculation. The stationary $\alpha-\beta$ signal is transformed into rotating $d-q$ signal for calculating the phase difference between ripple voltage and ripple current. In this thesis, the dSPACE1104 control desk is used as a tool to calculate the battery impedance. The detailed dSPACE1104 impedance calculation procedure is discussed in the following section. 


\section{3 dSPACE1104 Control Desk}

\subsubsection{Introduction of dSPACE1104}

The Digital Signal Processing and Control Engineering (dSPACE) DS1104 unit provides control of data for processing via its $8 \mathrm{ADC}$ and 8 DAC channels, 40 digital IO, and 40 Slave IO pin with 12 channels of PWM. The simulated model is developed in MATLAB/Simulink, and downloaded into the DS1104. Control variables and outputs can be viewed or modified using control desk software designed by the dSPACE1104 console. It has the capability to handle the real time debugging and software adjustable PWM from $1.25 \mathrm{~Hz}$ to $5 \mathrm{MHz}$. The dSPACE1104 package is compatibility with few converter power stages, 4 PWM generation and 1 UART I/O with FIFO. To implement a real-time control loop using dSPACE1104 and MATLAB, we need the following items:

- dSPACE DS1104 R\&D Controller Board

- Dongle licenses on a USB flash disk

- dSPACE1104 and Real-Time Interface in Simulink

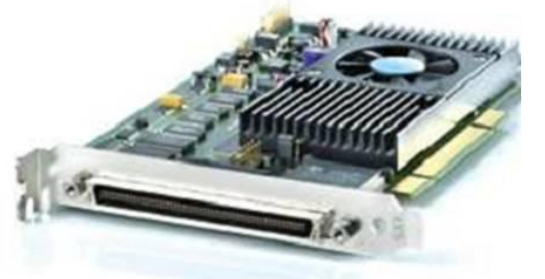

DS1104 control board

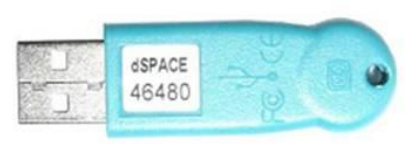

USB flash disk

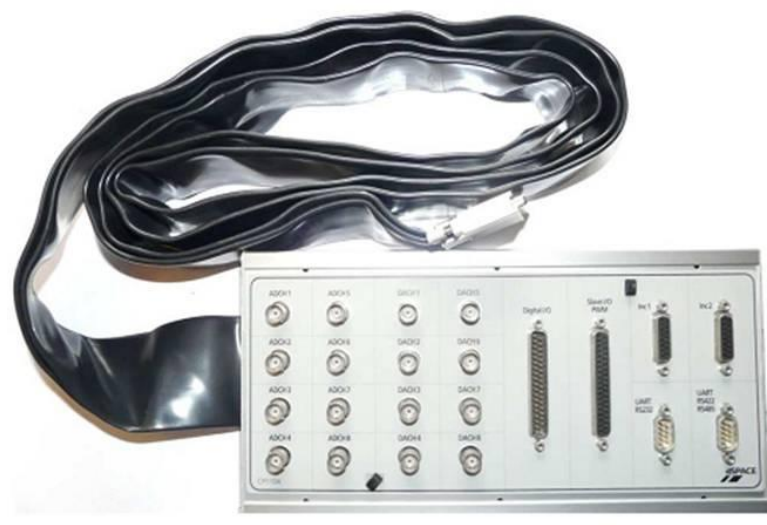

dSPACE1104 control interface

Fig. 4.1 dSPACE1104 elements [48] 


\subsubsection{Structure of a Real-Time Program}

To control the continuous system, we must use a discrete controller which has a sampling time period of T. The following Fig.4.2 shows the connections between the continuous system and its controller. The analog-to-digital converters (ADC) channel reads the information of the sensors and the digital-to-analog converters (DAC) channel apply the control commands to the system. The physical dynamic system have a time constant, from which derive a step size or sample time to control the program.

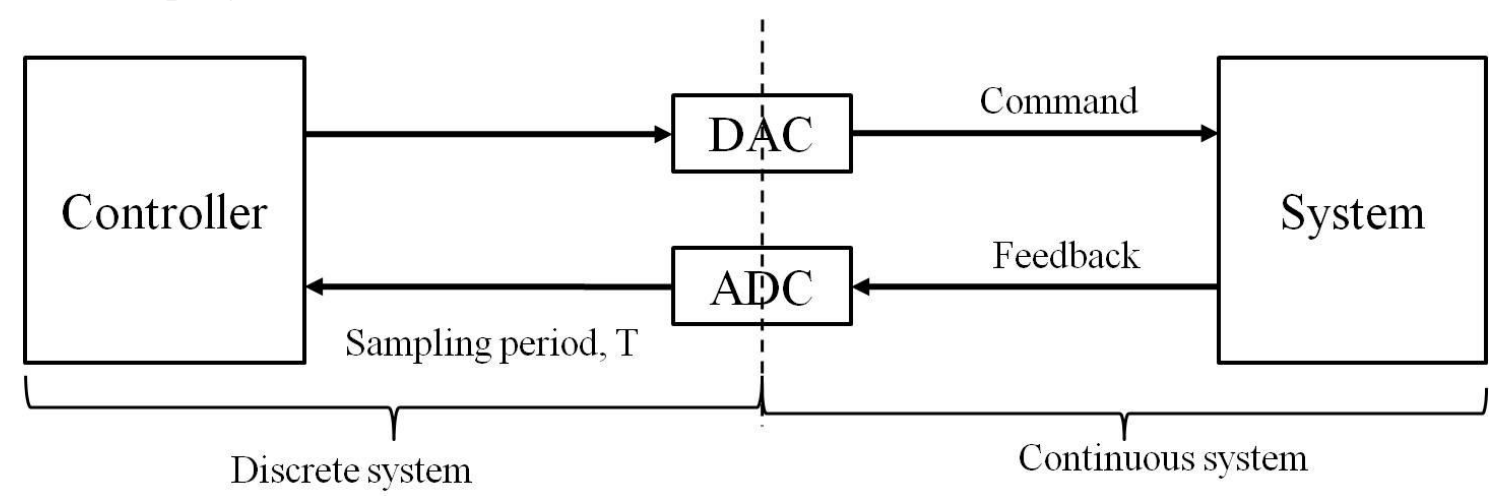

Fig. 4.2 Real time control structure of dSPACE1104

The overall structure of a real-time program can be simplified for explanation purposes into three main sections: Initialization, the real-time task or tasks, and the background. The initialization section is the code that is executed only once at the start of execution, upon download of the program. The next part of the program is the real-time part, represented by the sampling period. This part is the heart of the control program; read the inputs from an ADC channel, compute control signals, and write outputs with a DAC channel. Finally, the last section is the background; this is code executed in the "idle" time between the end of computation of a step and the start of the next step. 


\section{4 dSPACE1104 Impedance Calculation Procedure}

\subsection{1 d-q Transformation Method}

The impedance magnitude and phase calculation algorithm developed using ripple power method by MATLAB/Simulink and is downloaded as .sdf file into dSPACE1104 for computation. The block diagram of battery ac impedance calculation procedure is shown in Fig. 4.3. The single phase PLL circuit is used to produce the angle $\Phi$ for $d-q$ transformation of battery $\alpha-\beta$ ac ripple voltage and current signals. The impedance magnitude, $\left|Z_{T}\right|$ and the impedance angle, $\theta$ are obtained from the transformed $\mathrm{V}_{\mathrm{d}}, \mathrm{V}_{\mathrm{q}}, \mathrm{I}_{\mathrm{d}}$ and $\mathrm{I}_{\mathrm{q}}$ values.

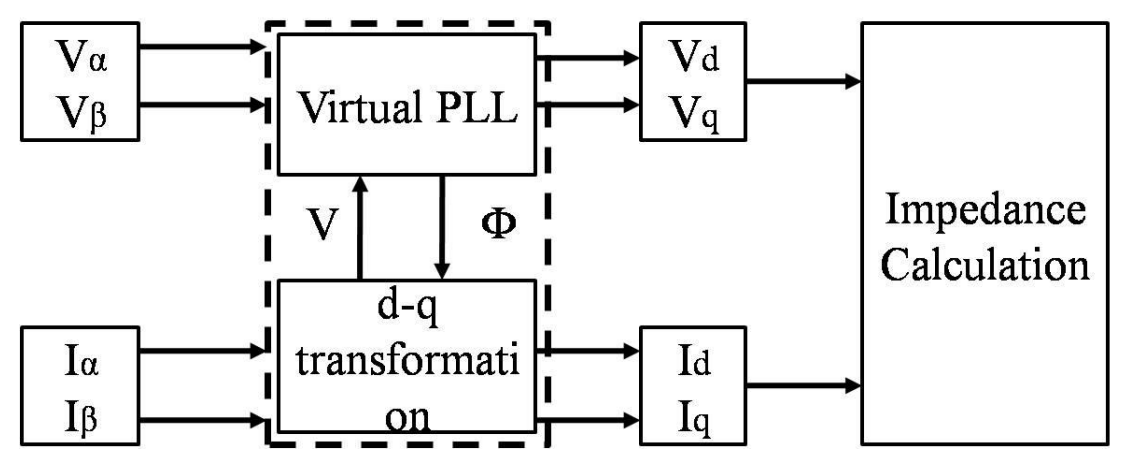

Fig. 4.3 dSPACE1104 impedance calculation process

\subsubsection{Stationary $\alpha-\beta$ to $d-q$ Rotating Co-ordinate System}

The $\alpha-\beta$ frame of battery ripple voltage/current are feedback to dSPACE1104 control desk through ADC channel. The d-q transformation mapped the $\alpha-\beta$ coordinate systems onto a twoaxis synchronous rotating reference frame. By obtaining angle $\theta$ from the PLL, the $\mathrm{d}-\mathrm{q}$ values of the voltage and current are calculated as follows:

$\left[\begin{array}{l}V_{d} \\ V_{q}\end{array}\right]=\left[\begin{array}{cc}\cos (\theta) & -\sin (\theta) \\ \sin (\theta) & \cos (\theta)\end{array}\right]\left[\begin{array}{l}V_{\alpha} \\ V_{\beta}\end{array}\right]$ 
$\left[\begin{array}{l}I_{d} \\ I_{q}\end{array}\right]=\left[\begin{array}{cc}\cos (\theta) & -\sin (\theta) \\ \sin (\theta) & \cos (\theta)\end{array}\right]\left[\begin{array}{c}I_{\alpha} \\ I_{\beta}\end{array}\right]$

\subsubsection{Total Impedance and Phase Angle Calculation}

The obtained $\mathrm{d}-\mathrm{q}$ values of the current and voltage are used for the ripple power calculation to obtain the phase difference between the current and the voltage. To calculate the magnitude of impedance used the d-axis and q-axis voltage and current is shown in (4.10). On the other hand, to calculate the impedance angle, $\varphi$, active and reactive powers of the ripple current and voltage are first calculated from (4.11) to (4.15) as follows:

$\left|Z_{\mathrm{T}}\right|=\frac{\sqrt{\left(V_{d}^{2}+V_{q}^{2}\right)}}{\sqrt{\left(I_{d}^{2}+I_{q}^{2}\right)}}$

$\mathrm{P}_{\text {ripple }}=\frac{\left(V_{d^{* I}}+V_{q} * I_{q}\right)}{2}$

$\mathrm{Q}_{\text {ripple }}=\frac{\left(V_{\left.d^{*} I_{d}-V_{q} * I_{q}\right)}\right.}{2}$

Apparent power can be obtained from the aforementioned power equations and from the active and apparent powers, we can derive the power factor angle as follows:

$\mathrm{S}_{\text {ripple }}=\sqrt{ }\left(P_{\text {ripple }}^{2}+Q_{\text {ripple }}^{2}\right)$

$\mathrm{PF}=\operatorname{Cos}(\Phi)=\frac{P_{\text {ripple }}}{S_{\text {ripple }}}$

The phase difference between the charging voltage and current of the battery is given as follows:

$\Phi=\operatorname{Cos}^{-1}\left(\frac{P_{\text {ripple }}}{S_{\text {ripple }}}\right)=\tan ^{-1}\left(\frac{V_{q}}{V_{d}}\right)$ 


\section{Chapter 5. Experimental Results}

The experimental setup used for investigating the performance of the filter sensing board, evaluating the capability of the ac ripple voltage sensing IC, and the impedance measurement result of Li-ion battery are presented in this chapter.

\subsection{Introduction}

In this work, a $12.8 \mathrm{~V}, 40 \mathrm{Ah} \mathrm{Li-ion} \mathrm{battery} \mathrm{manufactured} \mathrm{by} \mathrm{valance} \mathrm{technology} \mathrm{is} \mathrm{considered}$ for testing and ac signal measurement purpose. An experimental setup must to be prepared to measure the battery online ac impedance using SRC emulator. The battery is charged at dc constant current (C/8-rate) with a $\pm 1 \mathrm{~A}$ sinusoidal ripple current perturbation at different frequencies within $20 \mathrm{~Hz}$ to $2.5 \mathrm{kHz}$ range. The experimental setup is shown in Fig. 5.1, the dc power source $\mathrm{ABC} 150$, ac power source AMX3120, programmable load Chroma 6803 and resistive load are used to generate the SRC charging current. The experimental test result of SRC signal generation, signal measurement and battery impedance calculation results are described briefly in this chapter.

\subsection{Experimental Result}

\subsubsection{AC Source Perturbation}

In this method, the battery is charged by $5 \mathrm{~A}_{\mathrm{dc}} \pm 1 \mathrm{~A}_{\mathrm{ac}}$ at $720 \mathrm{~Hz}$. To make this ac ripple current, the ac source is programmed at line to line voltage at $18.66 \mathrm{~V}_{\mathrm{pp}}$ in $3-\Phi$ condition. The dc power supply is set at $58.6 \mathrm{~V}$ to charge the battery at $5 \mathrm{~A}$. The dc resistive load $(9 \Omega, 1 \mathrm{~kW})$ regulate the dc charging current in CC mode. The experimental test result is shown in Fig. 5.2(a). The yellow trace indicates, the total charging current, $5 \mathrm{~A}_{\mathrm{dc}} \pm 1 \mathrm{~A}_{\mathrm{ac}}$ while the green trace depicts the battery terminal voltage is $13.6 \mathrm{~V}_{\mathrm{dc}} \pm 15 \mathrm{mV}_{\mathrm{ac}}$. The blue and purple trace represents the ac voltage drop \pm $15 \mathrm{mV}_{\mathrm{ac}}$ due to $\pm 1 \mathrm{~A}_{\mathrm{ac}}$ ac ripple current excitation, respectively. 


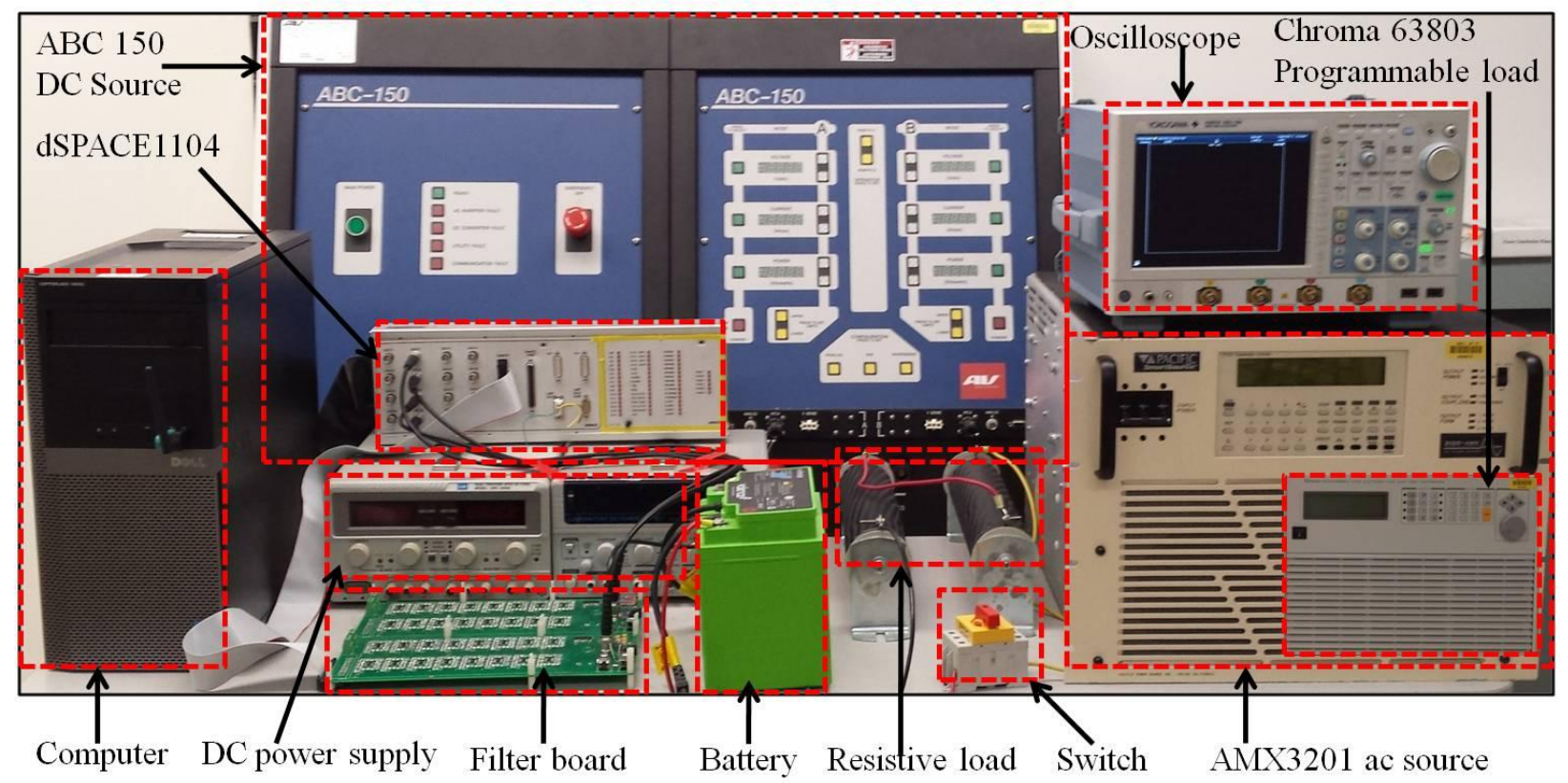

Fig. 5.1 Experimental set up for measuring battery ac impedance

\subsubsection{Programmable Load Perturbation}

In programmable load perturbation technique, the dc power supply is programmed at $58.6 \mathrm{~V}_{\mathrm{dc}}$ and the $9 \Omega, 1 \mathrm{~kW}$ resistive load determines the dc charging current same as the ac source perturbation approach. The programmable load (PL) is connected in parallel with the battery and the dc power supply. The PL is programmed as follows; $\mathrm{I}_{\text {set }}$ is $5 \mathrm{~A}$ and, $\mathrm{I}_{\mathrm{pmax}}$ is $7.8 \mathrm{~A}$ in dc rectified RLC load mode at $60 \mathrm{~Hz}$. Fig. 5.2(b) represents the corresponding test result with the programmable load perturbation technique. The yellow and green trace depicts the battery charging current is $4.7 \mathrm{~A}_{\mathrm{dc}}$ $\pm 0.25 \mathrm{~A}_{\mathrm{ac}}$ and corresponding terminal voltage is $13.6 \mathrm{~V}_{\mathrm{dc}} \pm 3.5 \mathrm{mV}_{\mathrm{ac}}$. The purple and blue traces represent the battery ac charging current and ac voltage response across the battery respectively. 


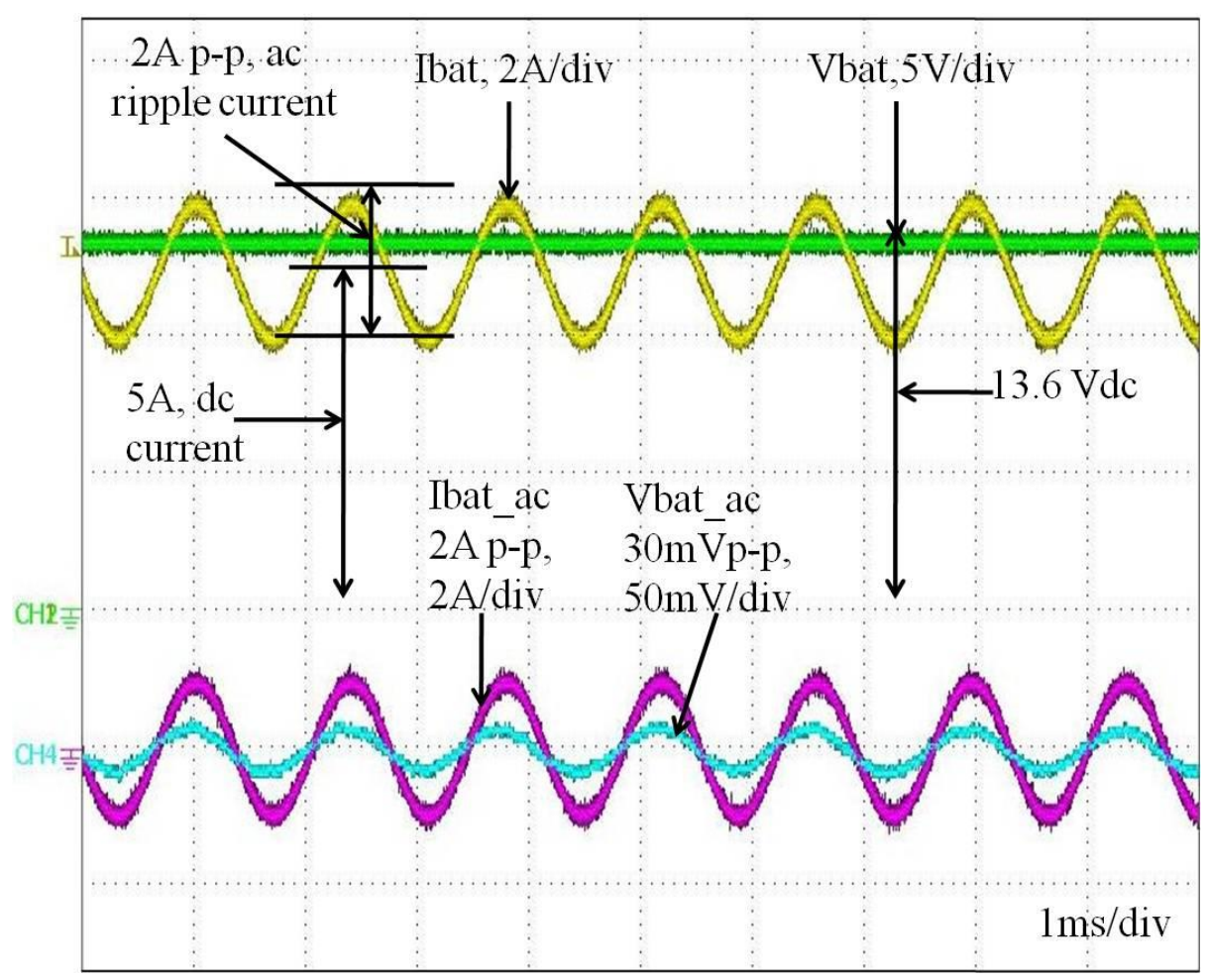

(a)

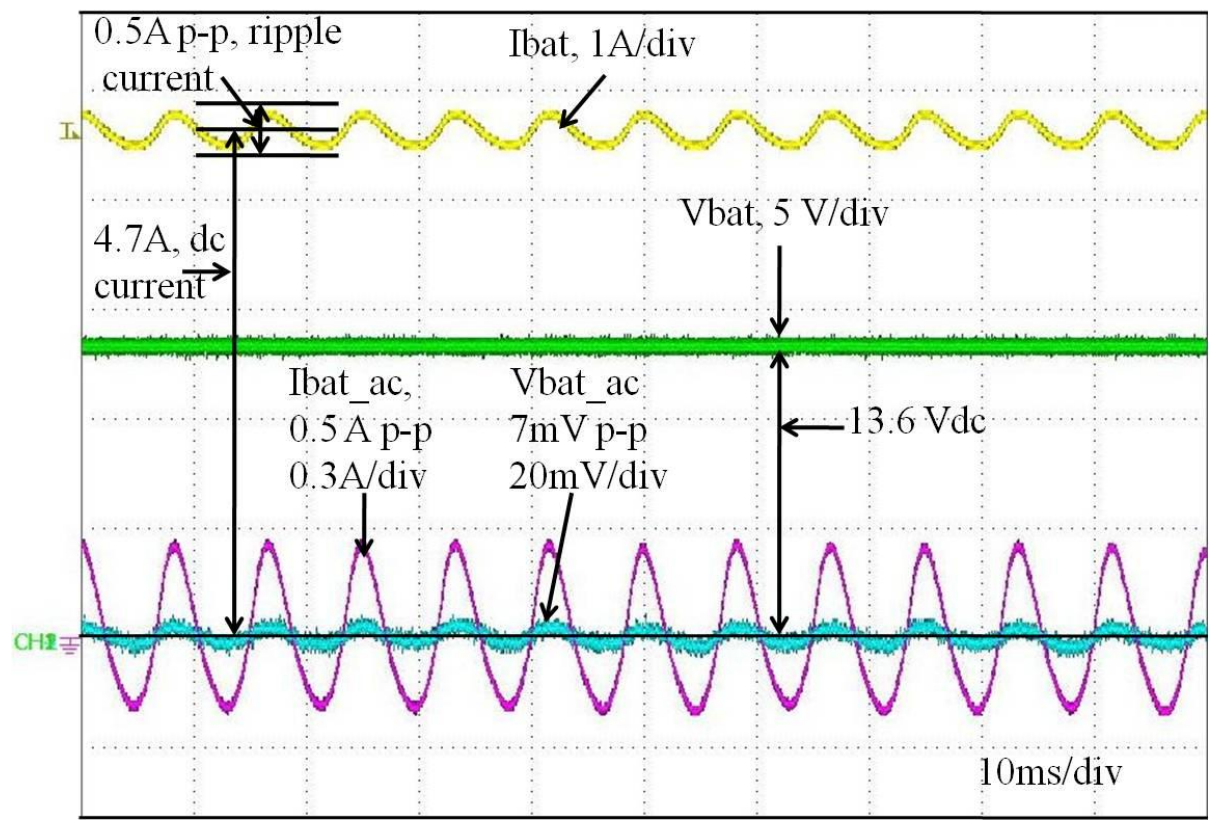

(b)

Fig. 5.2 SRC signal generation (a) ac source (b) programmable load 
From the experimental results, it is found that the SRC emulator can be emulated using the Chroma 63803 programmable load by operating in dc mode with it programmed in the RLC load condition. The limitations of PL perturbation technique are; 1) it requires higher dc current through the programmable load to produce the ac ripple perturbation, and 2) lower ac frequency sweep range. The experimental test shows, the PL impact on the dc current and produces $0.5 \mathrm{~A}$ peak-to-peak ripple by drawing 5.0 $\mathrm{A}_{\mathrm{dc}}$ current from dc power source. The maximum current limit of PL is $36 \mathrm{~A}_{\mathrm{rms}}$ at $3.6 \mathrm{~kW}$ and frequency changing range from $40 \mathrm{~Hz}$ to $400 \mathrm{~Hz}$.

\subsection{Signal Measurement}

\subsubsection{Current Sensor Output}

The current sensor output is shown in Fig.5.3. The purple trace indicates the output of ACS712 sensor IC. The yellow trace indicates the input line current while the green trace present the sensor output, respectively. The bandwidth of current sensor is designed at $93 \mathrm{kHz}$ for decreasing the signal rising time, $1.7 \mathrm{us}$. The phase delay between the input current and the output current is negligible.

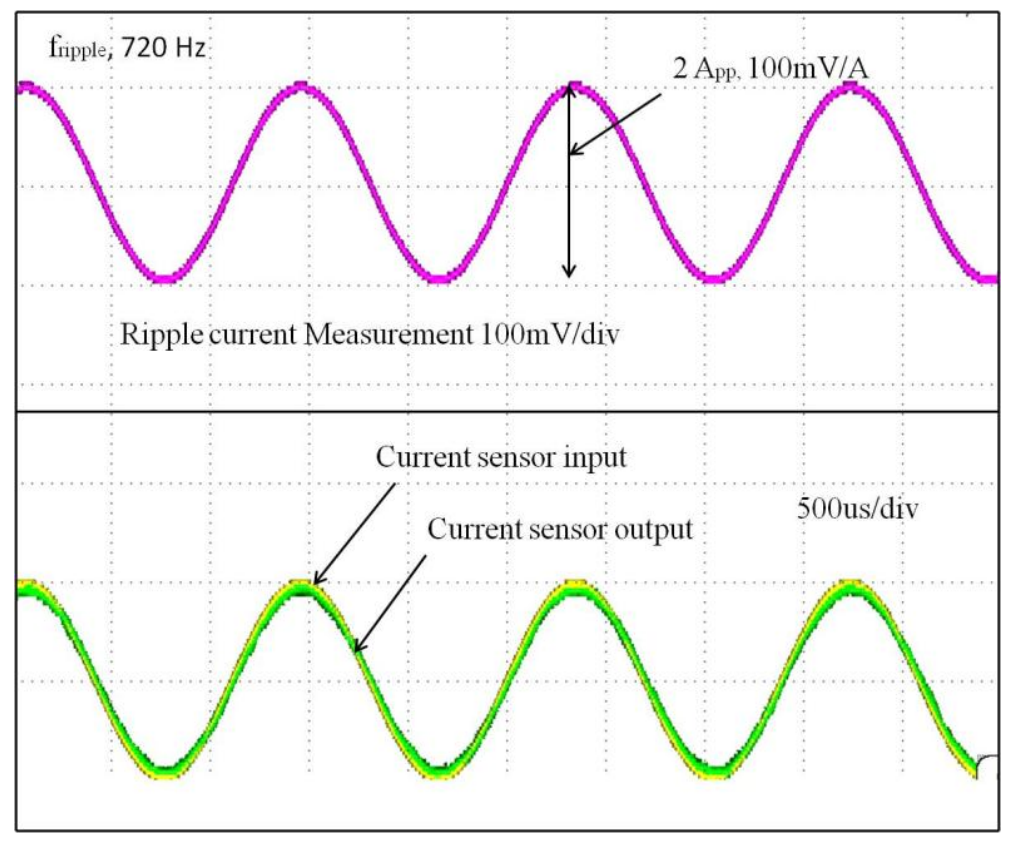

Fig.5.3 Current sensor output at $720 \mathrm{~Hz}$ 


\subsubsection{Voltage Sensor Output}

In order to measure, the battery ac ripple voltage with a higher measuring accuracy. The widely used AMC1200 and ACPLC870 voltage sensors are not suitable for battery ripple voltage measurement application. Since the battery ac voltage response is in $\mathrm{mV}$ range, a higher accuracy with wider input range, and larger bandwidth voltage sensors are required to measure the low ranges ripple voltage accurately. The summary of the measuring capability and usability of different voltage sensing ICs are shown in Table-I.

TABLE I: Ripple voltage sensing IC

\begin{tabular}{|c|c|c|c|c|c|c|}
\hline & \multicolumn{6}{|c|}{ Voltage Sensor IC } \\
\hline & Index & AMC1200 & ACPLC870 & INA217 & INA154 & AD8276 \\
\hline \multirow{7}{*}{ Features } & IC Type & $\begin{array}{l}\text { Differential } \\
\text { isolation } \\
\text { amplifier }\end{array}$ & $\begin{array}{l}\text { Optically } \\
\text { isolated } \\
\text { voltage } \\
\text { sensor }\end{array}$ & $\begin{array}{l}\text { Instrumentation } \\
\text { amplifier }\end{array}$ & $\begin{array}{l}\text { Difference } \\
\text { amplifier }\end{array}$ & $\begin{array}{l}\text { Difference } \\
\text { amplifier }\end{array}$ \\
\hline & $\begin{array}{l}\text { Supply } \\
\text { voltage }\end{array}$ & $5 \mathrm{~V}_{\mathrm{dc}}$ & 3 to $5.5 \mathrm{~V}_{\mathrm{dc}}$ & $( \pm 4.5$ to \pm 18$) \mathrm{V}_{\mathrm{dc}}$ & $\begin{array}{c}( \pm 4 \text { to } \pm 18) \\
V_{\mathrm{dc}}\end{array}$ & $\pm 15 \mathrm{~V}_{\mathrm{dc}}$ \\
\hline & Input range & $\pm 250 \mathrm{mV}$ & 0 to $2 \mathrm{~V}$ & $\pm 18.5 \mathrm{~V}$ & 0 to $\pm 30 \mathrm{~V}$ & $\pm 30 \mathrm{~V}$ \\
\hline & IC gain, $\mathrm{G}$ & 8 & Unity & Variable & Unity & Unity \\
\hline & $\begin{array}{l}\text { Measureme } \\
\text { nt accuracy }\end{array}$ & $0.5 \%$ & $\pm 3 \%$ & $\begin{array}{l}\mathrm{G}=1, \pm 0.25 \% \\
\mathrm{G}=10, \pm 0.7 \% \\
\mathrm{G}=100, \pm 3.2 \%\end{array}$ & $0.05 \%$ & $0.1 \%$ \\
\hline & Bandwidth & $60 \mathrm{kHz}$ & $100 \mathrm{kHz}$ & $100 \mathrm{kHz}$ at $\mathrm{G}=100$ & $3 \mathrm{MHz}$ & $550 \mathrm{kHz}$ \\
\hline & Rise time & $\begin{array}{c}1.6 \mathrm{us} \\
\mathrm{R}_{\mathrm{L}}=1.7 \mathrm{k} \\
\mathrm{C}_{\text {out }}=1 \mathrm{uF}\end{array}$ & $\begin{array}{c}\text { 3.6us } \\
\mathrm{R}_{\mathrm{L}}=36 \Omega, \\
\mathrm{C}_{\text {out }}=100 \mathrm{nF}\end{array}$ & $\begin{array}{c}2 \text { us } \\
\mathrm{R}_{\mathrm{L}}=2 \mathrm{k}\end{array}$ & $\begin{array}{c}2 \text { us } \\
\mathrm{R}_{\mathrm{L}}=2 \mathrm{k}\end{array}$ & $\begin{array}{c}15 \text { us } \\
\mathrm{R}_{\mathrm{L}}=10 \mathrm{k}\end{array}$ \\
\hline \multirow[t]{2}{*}{ Compatibility } & $\begin{array}{l}\text { Voltage } \\
\text { sensing }\end{array}$ & $\begin{array}{l}\text { - VDC } \\
\text { need } \\
\text { - High } \\
\text { level ac } \\
\text { voltage } \\
\text { - Motor } \\
\text { drives }\end{array}$ & $\begin{array}{l}\text { - VDC need } \\
\text { - High level } \\
\text { ac voltage } \\
\text { - DC link } \\
\text { voltage } \\
\text { - Motor } \\
\text { drives } \\
\end{array}$ & $\begin{array}{l}\text { - No need VDC } \\
\text { up to } \pm 18 \mathrm{~V} \\
\text { - Industrial } \\
\text { instrument } \\
\text { - Medical } \\
\text { application }\end{array}$ & $\begin{array}{l}\text { - No need VDC } \\
\text { up to } \pm 30 \mathrm{~V} \\
\text { - Industrial } \\
\text { instrument }\end{array}$ & $\begin{array}{l}\text { - No need } \\
\text { VDC up } \\
\text { to } \pm 30 \mathrm{~V} \\
\text { - Portable, } \\
\text { battery } \\
\text { powered } \\
\text { equipment }\end{array}$ \\
\hline & $\begin{array}{l}\text { Battery ac } \\
\text { ripple (few } \\
\text { mili volt) }\end{array}$ & No & No & Higher noise & Yes & Yes \\
\hline \multirow[b]{2}{*}{ Usability } & $\begin{array}{c}\text { Measureme } \\
\mathrm{nt}\end{array}$ & $\begin{array}{c}\text { DC \& AC } \\
\text { voltage }\end{array}$ & $\begin{array}{c}\text { DC \& AC } \\
\text { voltage }\end{array}$ & $\begin{array}{c}\text { DC \& AC } \\
\text { voltage }\end{array}$ & $\begin{array}{l}\mathrm{DC} \& \mathrm{AC} \\
\text { voltage }\end{array}$ & $\begin{array}{c}\text { DC \& AC } \\
\text { voltage }\end{array}$ \\
\hline & Application & $\begin{array}{l}\text { - Isolation } \\
\text {-UPS } \\
\text {-Frequency } \\
\text { inverter } \\
\text { - Low } \\
\text { torque } \\
\text { ripple }\end{array}$ & $\begin{array}{l}\text { - Isolation } \\
\text { - Solar } \\
\text { inverter } \\
\text { - Data } \\
\text { acquisition }\end{array}$ & $\begin{array}{l}\text { - Transducer } \\
\text { amplifier } \\
\text {-Microphone } \\
\text { preamplifier } \\
\text { - Differential } \\
\text { receivers }\end{array}$ & $\begin{array}{l}\text { - Differential } \\
\text { input amplifier } \\
\text {-VCCS } \\
\text { - Differential } \\
\text { current receiver } \\
\text {-Synchronous } \\
\text { demodulator } \\
\end{array}$ & $\begin{array}{l}\text { - Voltage, } \\
\text { current } \\
\text { test \& } \\
\text { measurem } \\
\text { ent }\end{array}$ \\
\hline
\end{tabular}

* VDC is voltage divider circuit, VCCS is voltage controlled current source 


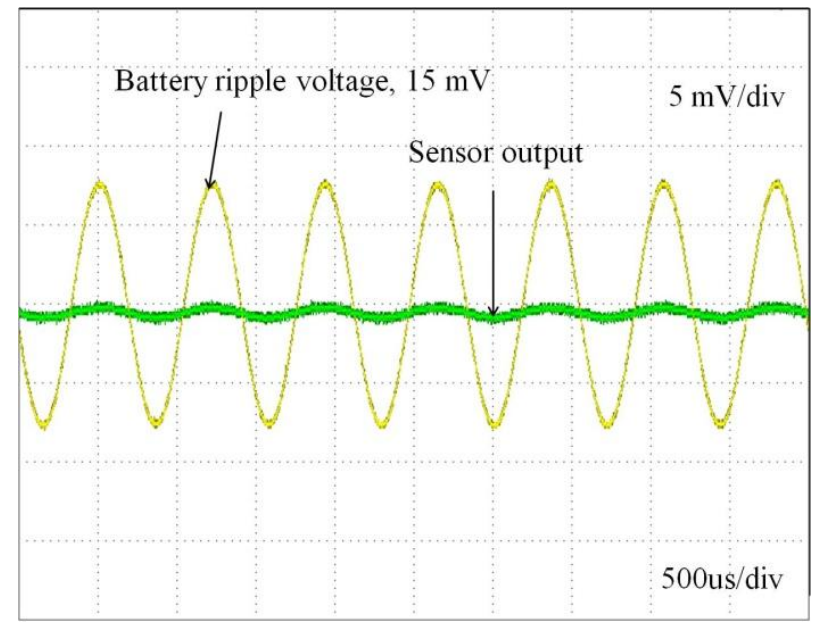

(a)

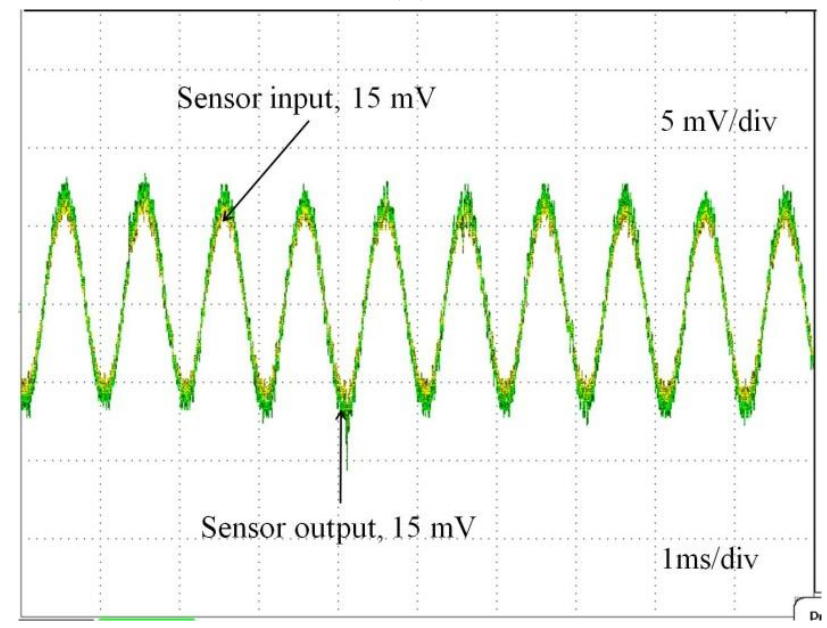

(c)

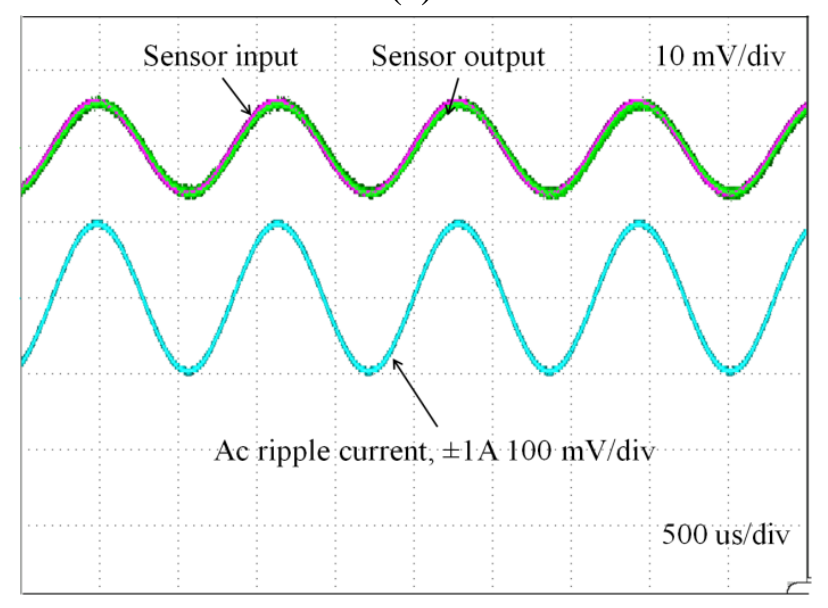

(e)

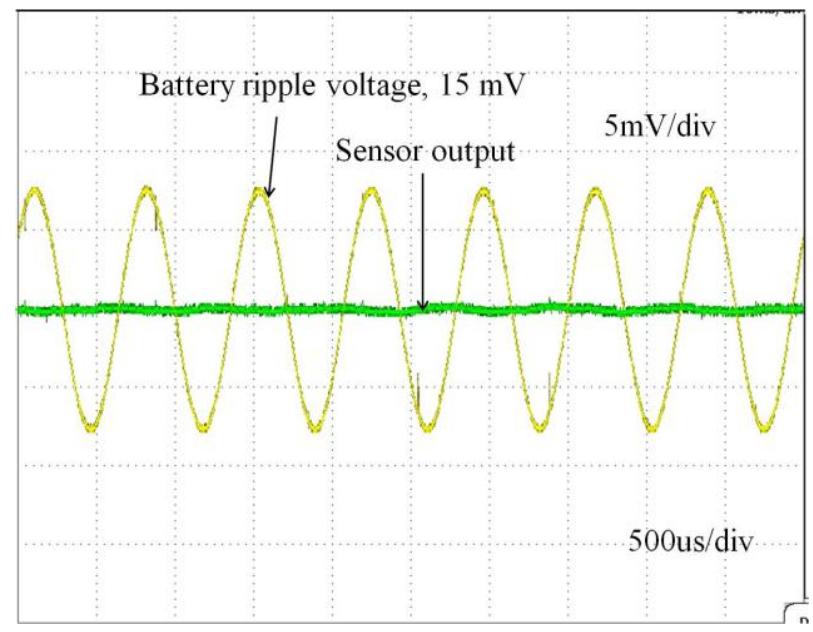

(b)

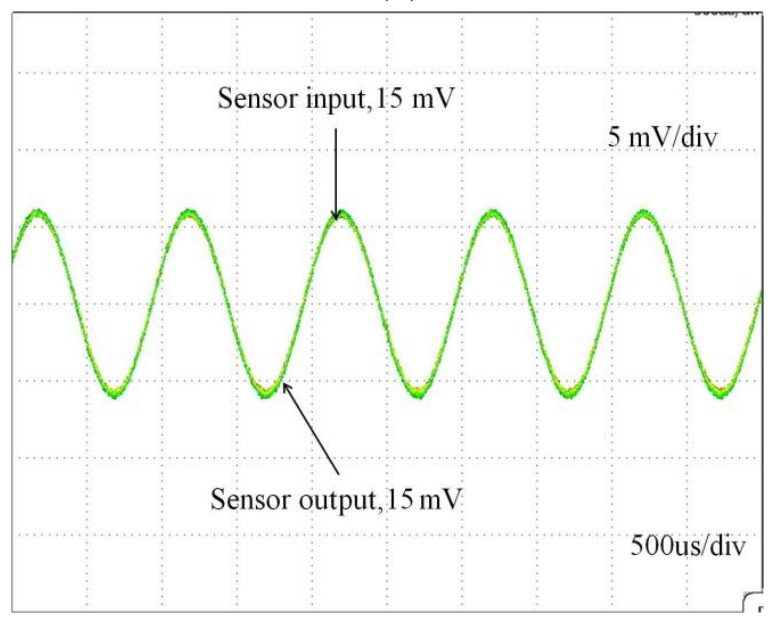

(d)

Fig. 5.4 Experimental waveforms of voltage sensor IC (a) AMC1200 (b) ACPLC870 (c) INA217 (d) INA154 and (e) AD8276 
AMC1200 is a well known voltage measuring IC in industrial application. A voltage divider circuit (VDC) is required to make compatible the IC maximum input voltage at $\pm 250 \mathrm{mV}$. In Fig. 5.4 (a) the yellow trace indicates the battery ac ripple voltage while the green trace represents the sensor output. The VDC also scaled-down the ripple voltage with the dc voltage. Therefore, AMC series ICs are not compatible for battery $\mathrm{mV}$ ranges ac ripple sensing application.

Similarly, the VDC is also needed in ACPLC870 voltage sensor in order to reduce the battery terminal voltage for fitting the IC input voltage range at $\pm 2 \mathrm{~V}$. The high voltage across rails needs to be scaled-down to make compatible with the input range of the optically isolation amplifier. So, the ACPLC870 IC can't measure perfectly the $\mathrm{mV}$ ranges ac ripple voltage. The battery ripple voltage measuring test result using ACPLC870 is shown in Fig. 5.4 (b). In addition, the voltage sensor produces differential outputs. In order to convert in a single ended signal an external high precision post amplifier is needed.

Fig. 5.4 (c) represents the test result of INA217 instrumentation amplifier. The yellow and green trace indicates the input and output signal of the sensor IC, respectively. The INA217 can measure the low range ac ripple voltage with adopting output noise due to lower measuring accuracy. The measuring error increases with increasing the IC gain selected by external gain parameter. Usually, the INA217 is a classical three-amp instrumentation amplifier designed for audio applications to amplify the low-level audio signals.

The INA154 IC can measure both low range ac and dc voltage with a higher accuracy, $0.05 \%$ up to $\pm 30 \mathrm{~V}$ input voltage range. The performance test result of INA154 is shown in Fig.5.4 (d).The input and output signals are in the same phase, due to low rise time, typically 2 us. 
The AD8276 is also a unity gain difference amplifier used for voltage and current measurements, and monitoring in portable battery powered equipment. It has a wide input range with $0.1 \%$ measuring accuracy. Fig. 5.4(e) represents the ac ripple voltage sensing capability of this IC. The output of AD8276 IC creates a phase delay with respect to input signal due to high response time, 15us compared to INA154.

\subsection{Filter Circuit Test Result}

\subsubsection{AC ripple extraction}

In order to verify, the PSIM simulation result the op-amp based practical circuit is implemented in hardware and the performance of dc offset filtering for extracting the low ranges ac ripple content is tested. The output of the low pass filter and differential amplifier are shown in Fig. 5.5. The yellow trace presents the ac ripple voltage signal at $720 \mathrm{~Hz}$. Whereas the green and purple trace indicate the low pass filter output and the differential amplifier output.

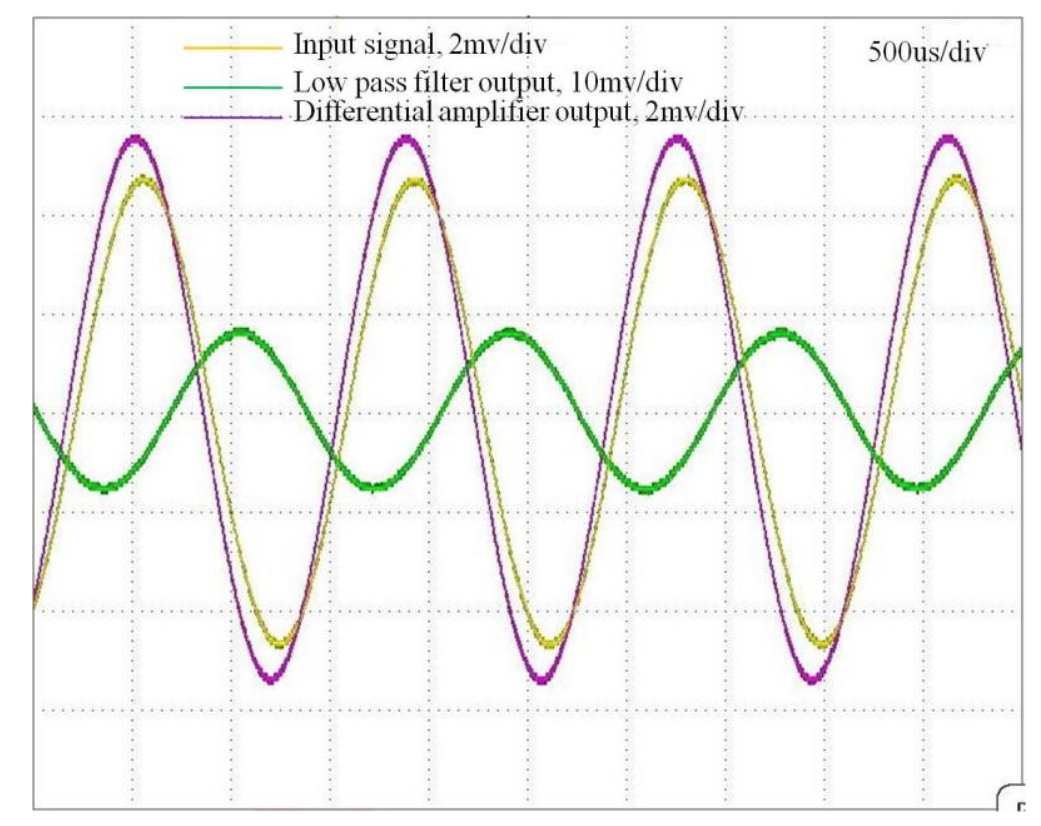

Fig.5.5 Experimental result of low pass filter, difference amplifier 


\subsubsection{Rotating $\alpha-\beta$ signal produce}

In order to calculate the impedance magnitude and phase angle using d-q transformation method, the rotating $\alpha-\beta$ frame is produced. The experimental picture captured by the oscilloscope is shown in Fig.5.6. In this experiment, two filter sensing boards are used for measuring the battery ac ripple voltage and ripple current separately. The PSIM simulation results and the practical Opamp based hardware circuit results are almost identical. The pass band filter creates the $\alpha$-axis signal while the all pass filter produces $90^{\circ}$ phase shift at the pass frequency which represent the $\beta$-axis signal. The yellow and green trace in Fig. 5.6(a) and Fig. 5.6(b) indicates the $\alpha-\beta$ frame of battery ripple voltage and ripple current signal, respectively. These ripple voltage and current information are used in impedance calculation algorithm for separating the impedance angle and magnitude.

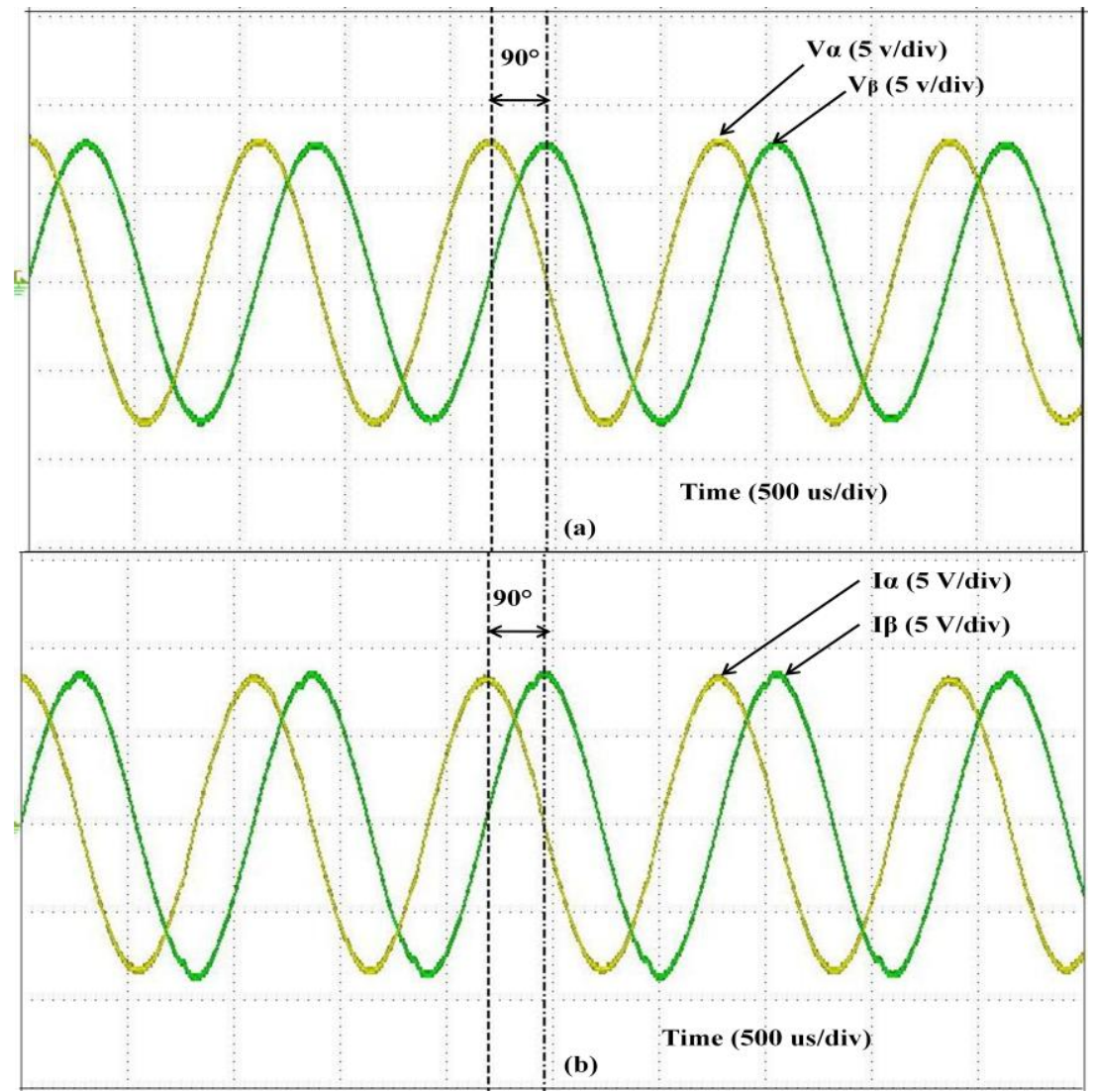

Fig.5.6 Experimental result of $\alpha-\beta$ signal for battery ac (a) voltage, and (b) current 


\subsection{Impedance Measurement Result}

The average impedance magnitude and phase angle are measured by injecting $2 \mathrm{~A}_{\mathrm{pp}}$ ac ripple current from the AMX3120 at different frequencies as shown in Table-I. The proposed system creates sinusoidal ripple currents from $20 \mathrm{~Hz}$ to $2000 \mathrm{~Hz}$. From these frequency sweeps, the battery impedance calculations were done by dSPACE1104 algorithm. To validate the ac ripple perturbation capability of AMX3120 ac power source in the proposed system, the impedance measurement of a $12.8 \mathrm{~V}, 40 \mathrm{Ah} \mathrm{Li}$-ion battery were performed at 20, 40, 60, 80, 100, 270, 340, $555,660,780,870,1500$ and $2000 \mathrm{~Hz}$ ripple frequency.

TABLE II: Battery Impedance Measurement Result

\begin{tabular}{|c|c|c|c|}
\hline SL\# & $\begin{array}{c}\text { Ripple } \\
\text { frequency, } \mathrm{Hz}\end{array}$ & $\begin{array}{c}\text { Real } \\
\text { impedance, } \mathrm{m} \Omega\end{array}$ & $\begin{array}{c}\text { Imaginary } \\
\text { impedance, } \mathrm{m} \Omega\end{array}$ \\
\hline 1 & 20 & 7.26 & 2.07 \\
\hline 2 & 40 & 6.38 & 2.34 \\
\hline 3 & 60 & 6.05 & 2.30 \\
\hline 4 & 80 & 5.83 & 1.94 \\
\hline 5 & 100 & 5.65 & 1.84 \\
\hline 6 & 270 & 5.25 & 1.33 \\
\hline 7 & 340 & 5.19 & 1.58 \\
\hline 8 & 560 & 5.55 & 1.43 \\
\hline 9 & 660 & 5.35 & 1.64 \\
\hline 10 & 780 & 5.52 & 1.56 \\
\hline 11 & 870 & 5.40 & 1.32 \\
\hline 12 & 1500 & 5.54 & 1.28 \\
\hline 13 & 2000 & 5.28 & 1.12 \\
\hline
\end{tabular}
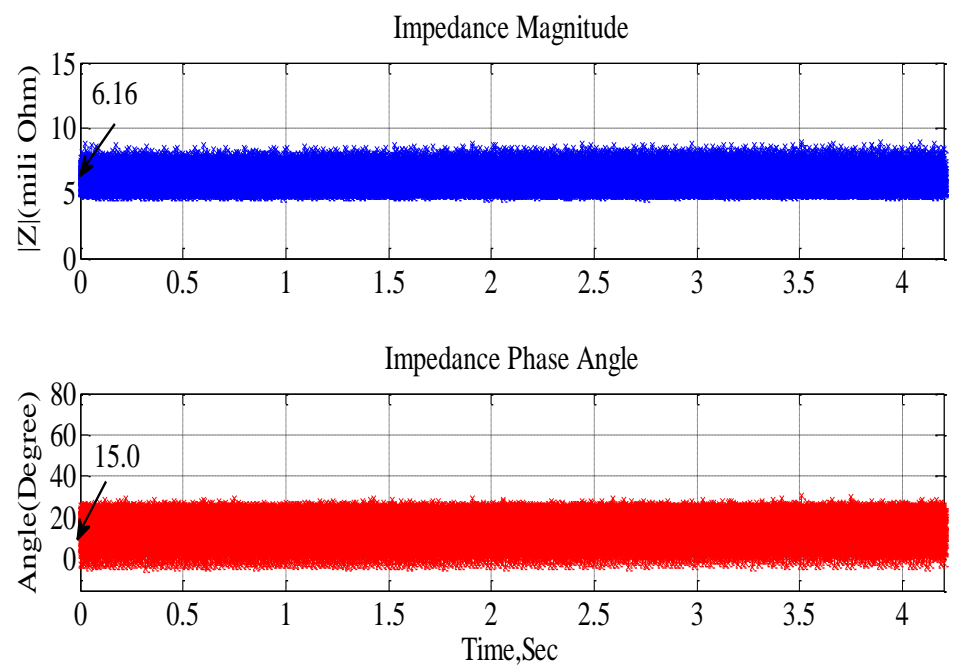

Fig.5.7 Battery impedance calculation by dSPACE1104 
The dSPACE1104 control interface converts the analog signal to digital at a $10 \mathrm{kHz}$ sampling rate for calculating the battery impedance magnitude and phase angle. The dSPACE1104 console was designed to plot the average value of calculated impedance magnitude and phase angle taking 10 thousand samples shown in Fig.5.7. The mean value of battery impedance magnitude and phase are $6.16 \mathrm{~m} \Omega$ and phase angle $15^{\circ}$ respectively at $1500 \mathrm{~Hz}$ ripple frequency.
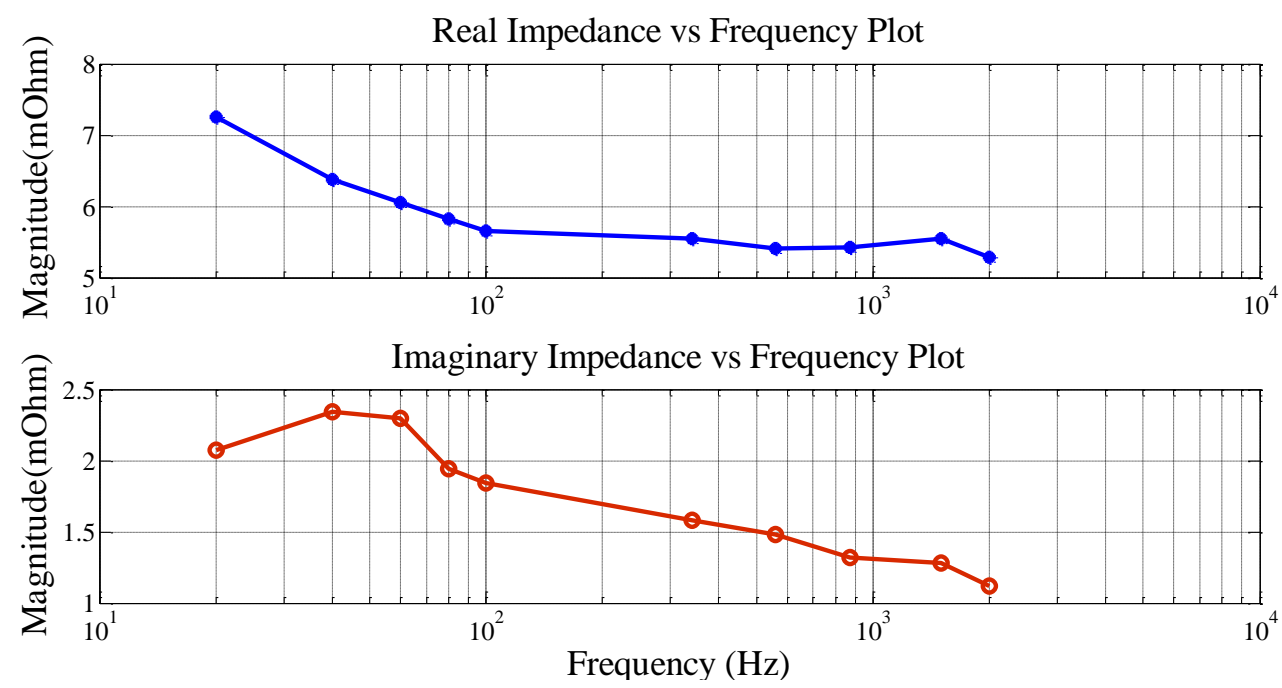

Fig. 5.8 Battery real and imaginary impedance at different frequency

Fig. 5.8 shows the real and imaginary impedance changes according to the ac sweep ripple frequency from $20 \mathrm{~Hz}$ to $2 \mathrm{kHz}$. The blue line is the measured real impedance and the red line is the imaginary impedance measured by the proposed method. The test results shows that, the magnitude of real and imaginary impedance both decreases with increasing the ac ripple frequency. At low frequency, around $60 \mathrm{~Hz}$, the battery imaginary part was maximum and decreased after and below this frequency.

TABLE III: Comparison of Battery Impedance Measurement Result

\begin{tabular}{|c|c|c|c|c|c|}
\hline SL & AC ripple & \multicolumn{2}{|c|}{ Reference [34] } & \multicolumn{2}{c|}{ Proposed Method } \\
\cline { 3 - 6 }$\#$ & frequency, $\mathrm{Hz}$ & $\begin{array}{c}\text { Real } \\
\text { impedance, } \mathrm{m} \Omega\end{array}$ & $\begin{array}{c}\text { Imaginary } \\
\text { impedance, } \mathrm{m} \Omega\end{array}$ & $\begin{array}{c}\text { Real } \\
\text { impedance, } \mathrm{m} \Omega\end{array}$ & $\begin{array}{c}\text { Imaginary } \\
\text { impedance, } \mathrm{m} \Omega\end{array}$ \\
\hline 1 & 20 & 10.00 & 2.80 & 7.26 & 2.07 \\
\hline 2 & 40 & 9.10 & 3.65 & 6.38 & 2.34 \\
\hline 3 & 60 & 8.60 & 3.60 & 6.05 & 2.30 \\
\hline 4 & 80 & 8.20 & 3.50 & 5.83 & 1.94 \\
\hline 5 & 100 & 7.90 & 3.30 & 5.55 & 1.82 \\
\hline
\end{tabular}


In order to verify, the battery impedance measurement results of the proposed system were compared with the corresponding ac ripple frequencies test result with SRC battery charger [34]. The comparative data of the proposed system and the referenced test results are shown in TableII. The impedance measurement results in the proposed system are in same trend with the reference data. From the comparison data, some differences were found due to the following reasons: 1) the battery impedance were measured only injecting the ac ripple current in the proposed technique whereas, the dc charging current and the ac ripple current both considered in [34] for this reason the real impedance are lower than the reference values. 2) the different SOC level of battery also impacted on the battery impedance values, 3) the dc offset effected on the impedance angle calculation in dSPACE1104, 4) the hardware measurements are subject to the sensing error of the sensor ICs, which operate with a (2-3) \% margin of measurement error and 5) phase angle delay between the output of current and voltage sensor ICs. The impedance test result shows that, the battery ac signal measurement using proposed filter sensing board for calculating impedance by dSPACE1104 is verified. The experimental result also shows that, the proposed SRC emulator can be used to validate the SRC charging performance before to implement in battery charger. 


\section{Chapter 6. Conclusion and Further Work}

Summarize the proposed battery online impedance measurement system with suggestions for further work and improvements are included in this chapter.

\subsection{Conclusion}

In this thesis, a method of measuring the battery online impedance by applying EIS impedance measurement techniques is presented. This was done by ac ripple perturbation using a SRC generator, signal measuring using a FSB and dSPACE1104 impedance calculation algorithm. The experimental results of SRC signal generator shows that, the SRC emulator can perturb the wide ranges ac ripple frequency current without a sinusoidal battery charging algorithm. The SRC emulator offers an easy way to validate the sinusoidal ripple current charging technique and is useful for measuring the battery impedance.

The performance and compatibility of different voltage sensing ICs were also investigated for measuring the battery low range ac ripple voltage. The experimental results shows that the AD8726 and INA154 difference amplifiers can be used for detecting and measuring the battery ac ripple with higher accuracy. In order to reduce the signal transformation steps and impedance calculation complexity, the proposed filter sensing board can be used to measure the battery online impedance along with the dSPACE1104 impedance calculation metod.

\subsection{Further Work}

Some suggestions regarding the potential future improvements of the proposed system and experimental setup are as follows:

1. The experimental setup can be upgraded to measure the battery impedance for reflecting the battery EIS and finding optimal charging frequency at minimum impedance point. To do this, 
replace the existing ac source (AMX3120) by a wide frequency range from few $100 \mathrm{mHz}$ to $1 \mathrm{kHz}$ ranges ac ripple current perturbation source.

2. Other designs for the low-pass and dc removing filter can be explored by removing the dc offset as much as possible, $100 \%$ would be the expectation level. Otherwise, the dc offset impacted on impedance angle calculation in dSPACE1104.

3. To design the voltage and current sensor response time as close as possible for avoiding the phase angle delay between sensor input and output signal for measuring the accurate impedance information, especially the impedance phase angle.

4. In d-q method, PLL circuit is needed for separating the impedance phase angle but it can't response instantaneously with swept the ac ripple frequency. Therefore, it can be replaced by the zero-crossing detector method for detecting impedance angle and avoiding the PLL circuit difficulties in existing impedance calculation method [50].

5. dSPACE1104 has the limitation of sampling rate at $10 \mathrm{kHz}$. So, for higher sampling rate up to $100 \mathrm{kHz}$ based real time simulator Opal-RT can be used for calculating the impedance magnitude and phase angle in the future.

7. The obtained battery impedance information can be used in the future for determining battery SOC, SOH, and finding the optimized charging current. 


\section{Appendix A. Publications List}

[1] Md. Kamal Hossain, S.M Rakiul Islam, and Sung-yeul Park, "Battery Online Impedance Measurement Using Sinusoidal Ripple Current Emulator," manuscript submitted for ECCE conference, 2017.

[2] M. K. Hossain, S. M. R. Islam and S. Y. Park, "Performance analysis of filter sensing board for measuring the battery online impedance,"2016 Asian Conference on Energy, Power and Transportation Electrification (ACEPT), Singapore, 2016, pp.1-6.

[3] Shawn Maxwell, S M Rakiul Islam, Md. Kamal Hossain and Sung Yeul Park, "Capability, Compatibility, and Usability Evaluation of Hardware-in-the-Loop Platforms for DC-DC Converter," Proceedings of IEEE in Energy Conversion Congress Expo 2016, Milwaukee, Wisconsin, Sep 18-22, 2016

[4] S M Rakiul Islam, Shawn Maxwell, Md. Kamal Hossain, Sung Yeul Park and Sung Min Park, " Reactive Power Distribution Strategy using Power Factor Correction Converters for Smart Home Application," Proceedings of IEEE in Energy Conversion Congress Expo 2016, Milwaukee, Wisconsin, Sep 18-22, 2016.

[5] S M Rakiul Islam, Md. Kamal Hossain, Sung Yeul Park,'Quantitative Analysis of District Energy in University Campuses: District energy trends in USA Campuses',107th annual conference \& trade show, Austin,TX, February 8-12, 2016. 


\section{Appendix B. References}

[1] F. A. Silva, "Lithium-Ion Batteries: Fundamentals and Applications [Book News]," in IEEE Industrial Electronics Magazine, vol. 10, no. 1, pp.58-59,March2016.

[2] J. B. Goodenough, H. D. Abruna, and M. V. Buchanan, "Basic Research Needs for Electrical Energy Storage. Report of the Basic Energy Sciences Workshop on Electrical Energy Storage, April 2-4, 2007," USDOE Office of Science, Washington, DC, USA, Apr. 2007.

[3] V. L. Teofilo, R. P. Hollandsworth, G. E. Mason, J. N. Nadell, M. J. Isaacson and E. A. Cuellar, "Lithium ion solid polymer electrolyte batteries for portable electronics and space applications," Fourteenth Annual Battery Conference on Applications and Advances. Proceedings of the Conference (Cat. No.99TH8371), Long Beach, CA, 1999, pp. 227-232.

[4] Chih-Wen Chuang, Ericson Go Chua, Yu-Sheng Lai and Wai-Chi Fang, "RF-powered Li-ion battery charger for biomedical applications," Life Science Systems and Applications Workshop, 2009. LiSSA 2009. IEEE/NIH, Bethesda, MD, 2009, pp. 187-189.

[5] S. Hu, X. Wang, R. Wang, J. Wu and X. He, "Hybrid sinusoidal-pulse charging strategy for Li-ion battery in electric vehicle application," Applied Power Electronics Conference and Exposition (APEC), 2015 IEEE, Charlotte, NC, 2015, pp. 3117-3123.

[6] J. Brunarie, A. M. Billard, S. Lansburg and M. Belle, "Lithium-ion (Li-ion) battery technology evolves to serve an extended range of telecom applications," Telecommunications Energy Conference (INTELEC), 2011 IEEE 33rd International, Amsterdam, 2011, pp. 1-9.

[7] P. Thounthong et al., "Differential flatness control approach for fuel cell/solar cell power plant with $\mathrm{Li}$-ion battery storage device for grid-independent applications," Power Electronics, Electrical Drives, Automation and Motion (SPEEDAM), 2014 International Symposium on, Ischia, 2014, pp. 261-266.

[8] R. S. Rubino, H. Gan and E. S. Takeuchi, "Implantable medical applications of lithium-ion technology," Seventeenth Annual Battery Conference on Applications and Advances. Proceedings of Conference (Cat. No.02TH8576), Long Beach, CA, 2002, pp. 123-127.

[9] A. Affanni, A. Bellini, G. Franceschini, P. Guglielmi and C. Tassoni, "Battery choice and management for new-generation electric vehicles," in IEEE Transactions on Industrial Electronics, vol. 52, no. 5, pp. 13431349, Oct. 2005.

[10] A. I. Stan, M. Świerczyński, D. I. Stroe, R. Teodorescu and S. J. Andreasen, "Lithium ion battery chemistries from renewable energy storage to automotive and back-up power applications - An overview,"2014 International Conference on Optimization of Electrical and Electronic Equipment (OPTIM), Bran, 2014, pp. 713-720.

[11] J. P. Aditya and M. Ferdowsi, "Comparison of NiMH and Li-ion batteries in automotive applications," 2008 IEEE Vehicle Power and Propulsion Conference, Harbin, 2008, pp. 1-6.

[12] S. Podder and M. Z. R. Khan, "Comparison of lead acid and Li-ion battery in solar home system of Bangladesh," 2016 5th International Conference on Informatics, Electronics and Vision (ICIEV), Dhaka, 2016, pp. 434-438.

[13] R. C. Cope and Y. Podrazhansky, "The art of battery charging," Fourteenth Annual Battery Conference on Applications and Advances. Proceedings of the Conference (Cat. No.99TH8371), Long Beach, CA, 1999, pp. 233-235.

[14] S. Skoog, "Parameterization of equivalent circuit models for high power lithium-ion batteries in HEV applications," 2016 18th European Conference on Power Electronics and Applications (EPE'16 ECCE Europe), Karlsruhe, 2016, pp. 1-10.

[15] Sunilkumar Vadivelu, "Investigation of sinusoidal ripple current charging techniques for Li-ion cells", M.Sc Thesis, KTH, Stockholm, Sweden 2016.

[16] "Five factors that affect battery life - Eaton," http://powerquality.eaton.com/thoughtleadership/Slides/BatteryLife/default.asp.

[17] "How heat and loading effect impact on battery life time", http://www.batteryuniversity.com /learn/article/how_heat_and_harsh_loading_reduces_battery_life

[18] F. Huet, "A review of impedance measurement for determination of the state-of-charge or state-of-health of secondary batteries," J. Power Source, vol. 70, no. 1, pp. 59-69, Jan. 1998. (IMPD)

[19] R. F. Nelson and M. A. Kepros, "AC ripple effects on VRLA batteries in float applications," Fourteenth Annual Battery Conference on Applications and Advances. Proceedings of the Conference (Cat. No.99TH8371), Long Beach, CA, 1999, pp. 281-289. 
[20] Y. D. Lee, S. Y. Park and S. B. Han, "Online Embedded Impedance Measurement Using High-Power Battery Charger," in IEEE Transactions on Industry Applications, vol. 51, no. 1, pp. 498-508, Jan.-Feb. 2015.

[21] S. Skoog, "Parameterization of equivalent circuit models for high power lithium-ion batteries in HEV applications," 2016 18th European Conference on Power Electronics and Applications (EPE'16 ECCE Europe), Karlsruhe, 2016, pp. 1-10.

[22] A. A. Hussein, A. A. Fardoun and S. S. Stephen, "An Online Frequency Tracking Algorithm Using Terminal Voltage Spectroscopy for Battery Optimal Charging," in IEEE Transactions on Sustainable Energy, vol. 7, no. 1, pp. 32-40, Jan. 2016.

[23] R. Koch and A. Jossen, "Impedance spectroscopy for battery monitoring with switched mode amplifiers," 2014 16th International Power Electronics and Motion Control Conference and Exposition, Antalya, 2014, pp. $496-501$

[24] D. A. Howey, P. D. Mitcheson, V. Yufit, G. J. Offer and N. P. Brandon, "Online Measurement of Battery Impedance Using Motor Controller Excitation," in IEEE Transactions on Vehicular Technology, vol. 63, no. 6, pp. 2557-2566, July 2014.

[25] E. Din, C. Schaef, K. Moffat and J. T. Stauth, "A Scalable Active Battery Management System With Embedded Real-Time Electrochemical Impedance Spectroscopy," in IEEE Transactions on Power Electronics, vol. 32, no. 7, pp. 5688-5698, July 2017.

[26] W. Huang and J. A. Abu Qahouq, "An Online Battery Impedance Measurement Method Using DC-DC Power Converter Control," in IEEE Transactions on Industrial Electronics, vol. 61, no. 11, pp. 5987-5995, Nov. 2014.

[27] J. A. A. Qahouq, "Online battery impedance spectrum measurement method," 2016 IEEE Applied Power Electronics Conference and Exposition (APEC), Long Beach, CA, 2016, pp. 3611-3615.

[28] E. Barsoukov and J. R. Macdonald, Impedance Spectroscopy: Theory, Experiment, and Applications. Hoboken and New Jersey: John Wiley \& Sons, Inc., 2nd ed., 2005.

[29] S. Rodrigues, N. Munichandraiah, and A. K. Shukla, "A review of state-of-charge indication of batteries by means of A.C. impedance measurements, ”Journal of Power Sources,vol.87,no. 1-2, pp. 12-20, 2000.

[30] A. Hentunen, T. Lehmuspelto and J. Suomela, "Time-Domain Parameter Extraction Method for ThéveninEquivalent Circuit Battery Models," in IEEE Transactions on Energy Conversion, vol. 29, no. 3, pp. 558-566, Sept. 2014.

[31] L. R. Chen, S. L. Wu, T. R. Chen, W. R. Yang, C. S. Wang and P. C. Chen, "Detecting of optimal Li-ion battery charging frequency by using AC impedance technique" Proc. 4th IEEE International Conference on Industrial Electronics and Applications (ICIEA), May 2009.

[32] Chen, Liang-Rui, et al. "Sinusoidal-ripple-current charging strategy and optimal charging frequency study for Li-ion batteries." Industrial Electronics, IEEE Transactions on 60.1 (2013): 88-97.

[33] Y. D. Lee and S. Y. Park, "Electrochemical State-Based Sinusoidal Ripple Current Charging Control," in IEEE Transactions on Power Electronics, vol. 30, no. 8, pp. 4232-4243, Aug. 2015.

[34] A. Xenophontos, J. Rarey, A. Trombetta and A. M. Bazzi, "A flexible low-cost photovoltaic solar panel emulation platform," 2014 Power and Energy Conference at Illinois (PECI), Champaign, IL, 2014.

[35] A. F. Ebrahim, S. M. W. Ahmed, S. E. Elmasry and O. A. Mohammed, "Implementation of a PV emulator using programmable DC power supply," SoutheastCon 2015, Fort Lauderdale, FL, 2015, pp. 1-7

[36] A. Rachid, F. Kerrour, R. Chenni and H. Djeghloud, "PV emulator based buck converter using dSPACE controller," 2016 IEEE 16th International Conference on Environment and Electrical Engineering (EEEIC), Florence, 2016, pp. $1-6$.

[37] R. V. Gokhale, S. M. Mahajan, B. W. Abegaz and R. P. M. Craven, "Development of a real time wind turbine emulator based on RTDS using advanced perturbation methods," 2015 IEEE 15th International Conference on Environment and Electrical Engineering (EEEIC), Rome, 2015, pp. 1713-1718

[38] J. M. Nye, J. G. de la Bat, M. A. Khan and P. Barendse, "Design and implementation of a variable speed wind turbine emulator," 2012 XXth International Conference on Electrical Machines, Marseille, 2012, pp. 2060-2065.

[39] S. Tammaruckwattana and K. Ohyama, "Experimental verification of variable speed wind power generation system using permanent magnet synchronous generator by wind turbine emulator," IECON 2012 - 38th Annual Conference on IEEE Industrial Electronics Society, Montreal, QC, 2012, pp. 5827-5832.

[40] I. Moussa, A. Bouallegue and A. Khedher, "Design and implementation of constant wind speed turbine emulator using Matlab/Simulink and FPGA," 2014 Ninth International Conference on Ecological Vehicles and Renewable Energies (EVER), Monte-Carlo, 2014, pp. 1-8. 
[41] [Online available] https://www.valence.com/products/standard -modules/xp-module/

[42] Operation Manual, "AC power Source, AMX Series". [Online available] http:// www.Manualslib.com

[43] Operation \& Programming Manual, "Programmable AC/DC Electronic Load, 63800 Series". [Online available] http:// www.chrommate.com

[44] M. K. Hossain, S. M. R. Islam and S. Y. Park, "Performance analysis of filter sensing board for measuring the battery online impedance," 2016 Asian Conference on Energy, Power and Transportation Electrification (ACEPT), Singapore, 2016, pp. 1-6.

[45] ACS712, "Current Measurement IC", data sheet. [Online available] http://www.digikey.com/

[46] [Online available] http://cdn.teledynelecroy.com/files/whitepapers/wp_differential_measurements.pdf and

[47] AD8276, "Voltage Measurement IC", data sheet. [Online available] http://www.digikey.com/

[48] MC1407B, "Multiplexer/Demultiplexer IC", data sheet. [Online available] http://www.digikey.com/

[49] [Online available] http://dspace.org/sites/dspace.org/files/archive/1_6_2Documentation/index.html

[50] C. R. Lashway, G. Constant, J. Theogene and O. Mohammed, "A real-time circuit topology for battery impedance monitoring," SoutheastCon 2016, Norfolk, VA, 2016, pp. 1-6.

[51] Patrick T. Moseley, Jurgen Garche, "Electrochemical Energy Storage for Renewable Sources and Grid Balancing [Text book]", in Elsevier press 2015, Waltham, MA 024451, USA.

[52] "Effect of AC Ripple Current on VRLA battery life", A technical note from the experts in business-critical continuity.

[53] S. Y. Cho, I. O. Lee, J. I. Baek and G. W. Moon, "Battery Impedance Analysis Considering DC Component in Sinusoidal Ripple-Current Charging," in IEEE Transactions on Industrial Electronics, vol. 63, no. 3, pp. 1561-1573, March 2016.

[54] A. Jossen, "Fundamentals of battery dynamics," Journal of Power Sources, vol. 154, no. 2, pp. 530-538, 2006.

[55] Gayakwad, Ramakant A.," Op-amps and linear integrated circuits [Text book]". Prentice-Hall, Inc., 1993.

[56] C. R. Lashway, G. Constant, J. Theogene and O. Mohammed, "A real-time circuit topology for battery impedance monitoring," South east Conference 2016, Norfolk, VA, 2016, pp. 1-6. 


\section{Appendix C. Filter Circuit Design}

The following table shows, the components value of the low pass and all pass filter circuits along with the corresponding channel frequencies.

Table IV Components value of low pass and all pass filter

\begin{tabular}{|c|c|c|c|c|c|c|c|c|c|c|c|c|c|c|c|}
\hline \multirow{2}{*}{$\begin{array}{l}\text { Ch. } \\
\#\end{array}$} & \multirow{2}{*}{$\begin{array}{l}\text { Freq } \\
(\mathrm{Hz})\end{array}$} & \multicolumn{7}{|c|}{ Low Pass Filter } & \multicolumn{7}{|c|}{ All Pass Filter } \\
\hline & & $\mathrm{R}_{6}$ & $\mathrm{R}_{7}$ & $\mathrm{R}_{14}$ & $\mathrm{R}_{16}$ & $\mathrm{C}_{1}$ & $\mathrm{C}_{2}$ & $\mathrm{C}_{3}$ & $\mathrm{R}_{2}$ & $\mathrm{R}_{3}$ & $\mathrm{R}_{11}$ & $\mathrm{R}_{12}$ & $\mathrm{R}_{4}$ & $\mathrm{R}_{5}$ & $\mathrm{C}_{4}$ \\
\hline 1 & 2000 & 0.12 & 0.12 & 0.0 & 0.0 & 0.47 & 0.47 & 0.47 & 0.12 & 0.51 & 0.12 & 0.51 & 0.12 & 0.51 & 0.47 \\
\hline 2 & 1500 & 0.15 & 0.15 & 0.10 & 0.10 & 0.10 & 0.10 & 0.10 & 0.22 & 6.8 & 0.22 & 6.8 & 0.22 & 6.8 & 0.10 \\
\hline 3 & 990 & 0.15 & 0.15 & 1.00 & 1.00 & 0.20 & 0.20 & 0.10 & 0.68 & 1.00 & 0.68 & 1.00 & 0.68 & 1.00 & 0.10 \\
\hline 4 & 915 & 0.15 & 0.15 & 1.00 & 1.00 & 0.20 & 0.20 & 0.10 & 1.50 & 0.22 & 1.50 & 0.22 & 1.50 & 0.22 & 0.10 \\
\hline 5 & 850 & 0.00 & 0.00 & 1.30 & 1.30 & 0.20 & 0.20 & 0.10 & 1.40 & 0.47 & 1.40 & 0.47 & 1.40 & 0.47 & 0.10 \\
\hline 6 & 780 & 0.00 & 0.00 & 1.43 & 1.43 & 0.20 & 0.20 & 0.10 & 1.00 & 1.00 & 1.00 & 1.00 & 1.00 & 1.00 & 0.10 \\
\hline 7 & 720 & 0.00 & 0.00 & 1.58 & 1.58 & 0.20 & 0.20 & 0.10 & 1.30 & 1.00 & 1.30 & 1.00 & 1.30 & 1.00 & 0.10 \\
\hline 8 & 660 & 0.10 & 0.10 & 1.60 & 1.60 & 0.20 & 0.20 & 0.10 & 1.40 & 1.00 & 1.40 & 1.00 & 1.40 & 1.00 & 0.10 \\
\hline 9 & 605 & 1.00 & 1.00 & 1.80 & 1.80 & 0.20 & 0.20 & 0.10 & 1.60 & 1.00 & 1.60 & 1.00 & 1.60 & 1.00 & 0.10 \\
\hline 10 & 555 & 1.00 & 1.00 & 1.00 & 1.00 & 0.20 & 0.20 & 0.10 & 1.80 & 1.00 & 1.80 & 1.00 & 1.80 & 1.00 & 0.10 \\
\hline 11 & 510 & 1.00 & 1.00 & 1.13 & 1.13 & 0.20 & 0.20 & 0.10 & 1.40 & 1.60 & 1.50 & 1.60 & 1.40 & 1.60 & 0.10 \\
\hline 12 & 460 & 1.40 & 1.40 & 1.00 & 1.00 & 0.20 & 0.20 & 0.10 & 0.00 & 1.60 & 0.00 & 1.57 & 0.20 & 1.40 & 0.22 \\
\hline 13 & 410 & 1.30 & 1.30 & 1.40 & 1.40 & 0.20 & 0.20 & 0.10 & 0.00 & 1.80 & 0.00 & 1.76 & 0.00 & 1.80 & 0.22 \\
\hline 14 & 340 & 1.40 & 1.40 & 0.10 & 0.10 & 0.47 & 0.47 & 0.22 & 1.00 & 1.13 & 1.00 & 1.12 & 1.00 & 1.13 & 0.22 \\
\hline 15 & 270 & 0.10 & 0.10 & 1.80 & 1.80 & 0.47 & 0.47 & 0.22 & 1.60 & 1.00 & 1.85 & 1.00 & 1.60 & 1.00 & 0.22 \\
\hline 16 & 200 & 1.00 & 1.00 & 1.43 & 1.43 & 0.47 & 0.47 & 0.22 & 0.00 & 1.60 & 0.00 & 1.60 & 0.00 & 1.60 & 0.47 \\
\hline 17 & 140 & 3.65 & 3.65 & 3.65 & 3.65 & 0.47 & 0.47 & 0.22 & 3.24 & 1.91 & 3.24 & 1.91 & 3.24 & 1.91 & 0.22 \\
\hline 18 & 100 & 3.3 & 3.3 & 1.8 & 1.8 & 0.22 & 0.22 & 0.22 & 3.00 & 0.39 & 3.00 & 0.39 & 3.00 & 0.39 & 0.47 \\
\hline 19 & 60 & 5.50 & 5.50 & 1.90 & 1.90 & 0.47 & 0.47 & 0.44 & 2.80 & 2.00 & 2.83 & 2.00 & 2.80 & 2.00 & 0.47 \\
\hline 20 & 40 & 9.5 & 9.5 & 3.3 & 3.3 & 0.22 & 0.22 & 0.22 & 13.0 & 5.1 & 13.0 & 5.1 & 13.0 & 5.1 & 0.22 \\
\hline 21 & 20 & 2.4 & 2.4 & 9.53 & 9.53 & 0.47 & 0.47 & 0.47 & 4.99 & 12.0 & 4.99 & 12.0 & 4.99 & 12.0 & 0.47 \\
\hline
\end{tabular}




\section{Appendix D. Hardware Circuit Design}

\section{D.1: Schematic Diagram of Filter Sensing Board}

The following Fig. D.1 and Fig. D.2 represents the schematic diagram of the filter circuit and filter sensing board with voltage sensing, signal encoding/decoding and others peripheral components respectively.

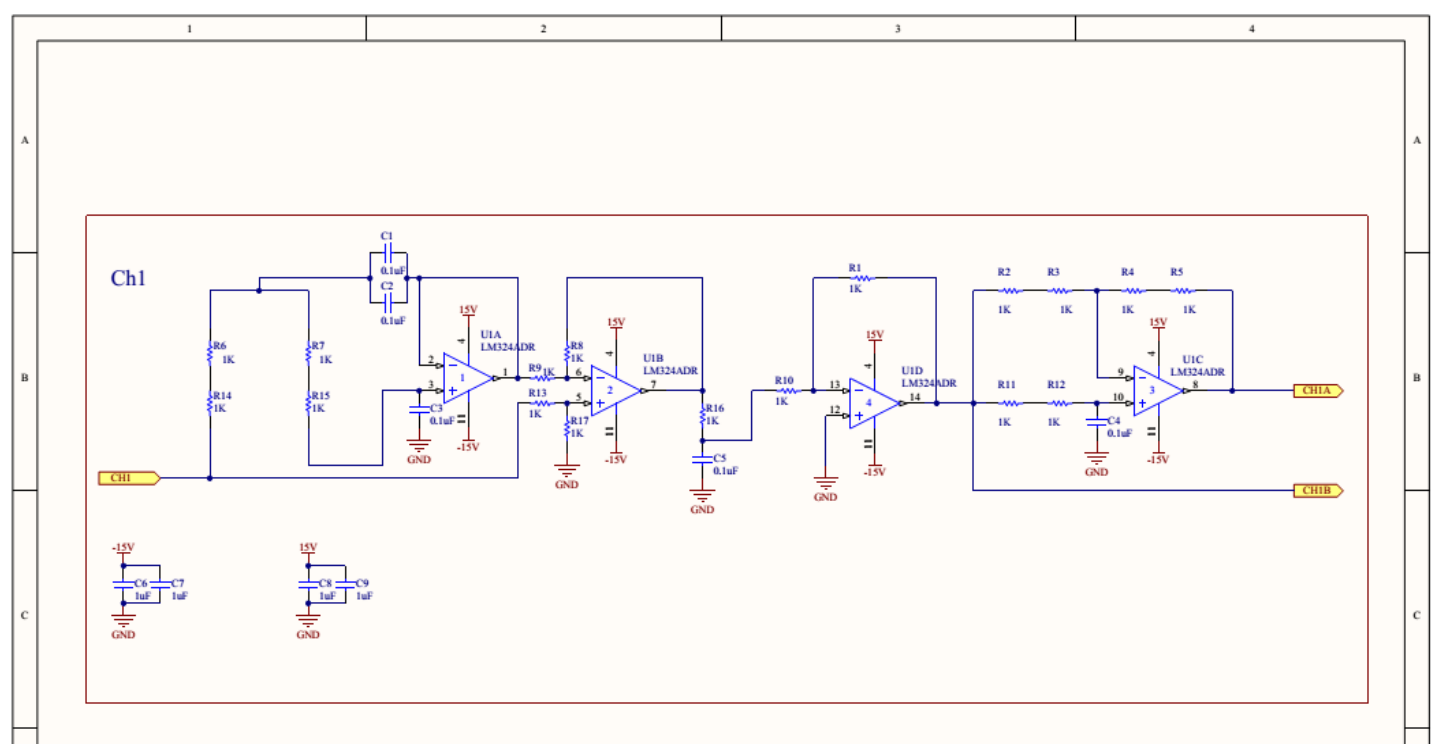

Fig. D.1 Schematic diagram of low pass, band pass, amplifier and all pass filter

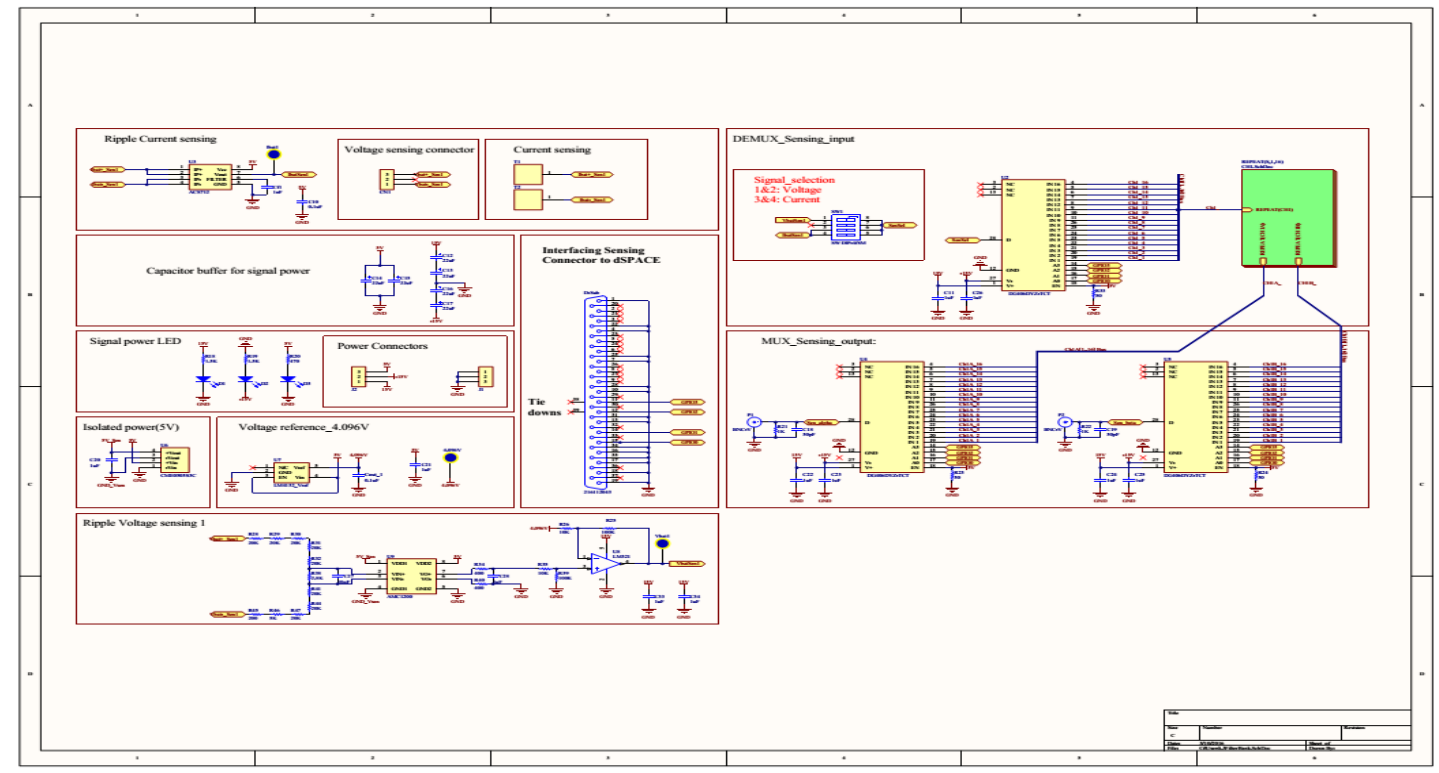

Fig. D.2 Schematic diagram of filter sensing board using altium circuit designing tool 
D.2 Hardware Implementation of Filter Sensing Board with Component Assembly:

The complete filter sensing circuit with component assembly for extracting the battery ac ripple content and creating the $\alpha-\beta$ signal is shown in Fig. D.4 and D.5.

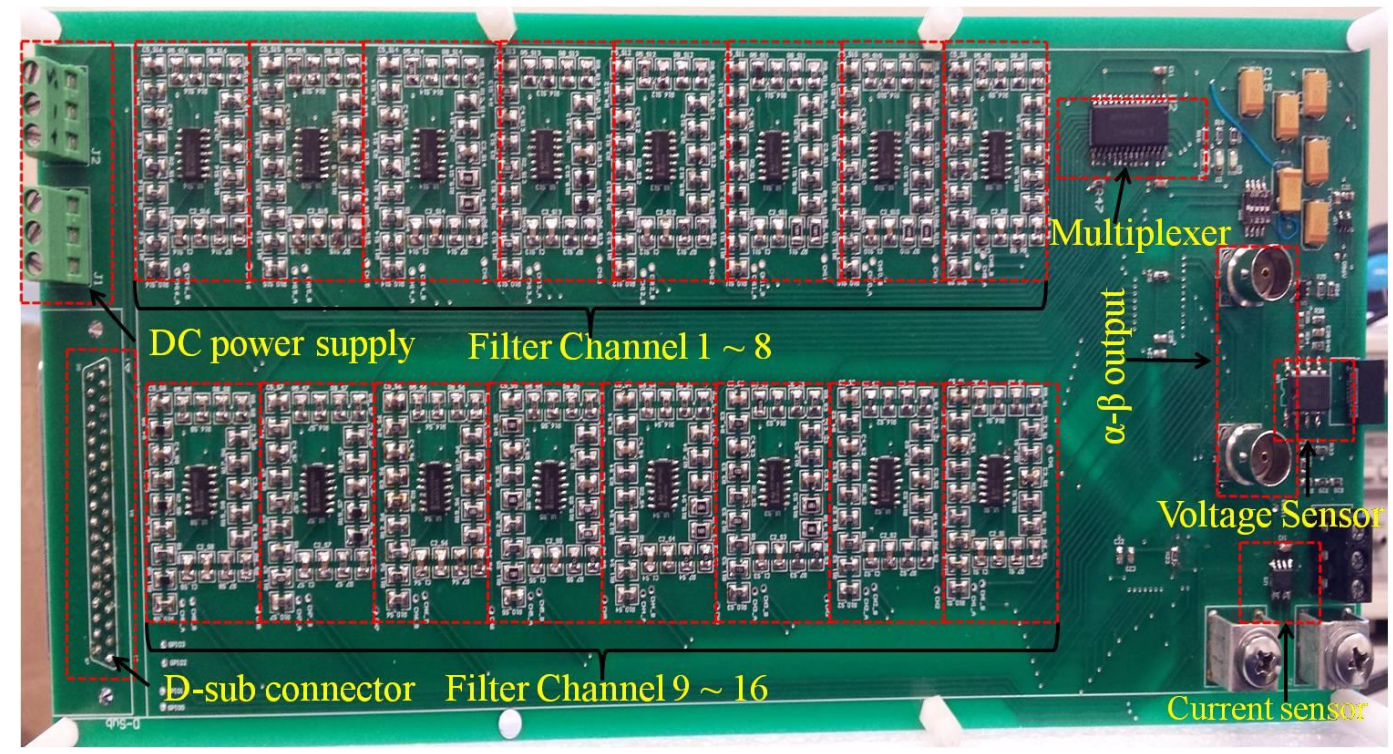

Fig. D.4 Top view of filter sensing board

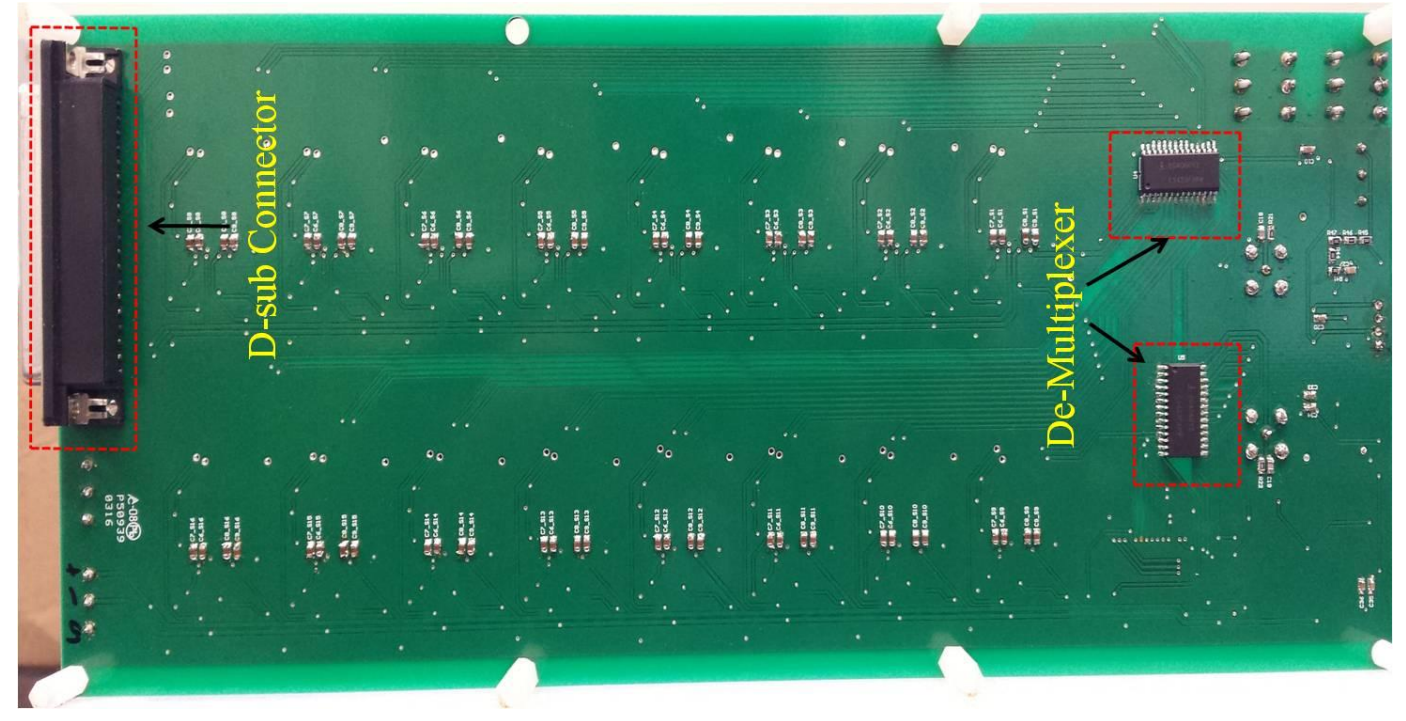

Fig. D.5 Bottom view of filter sensing board 
E. MARLAB/Simulink Impedance Calculation Model
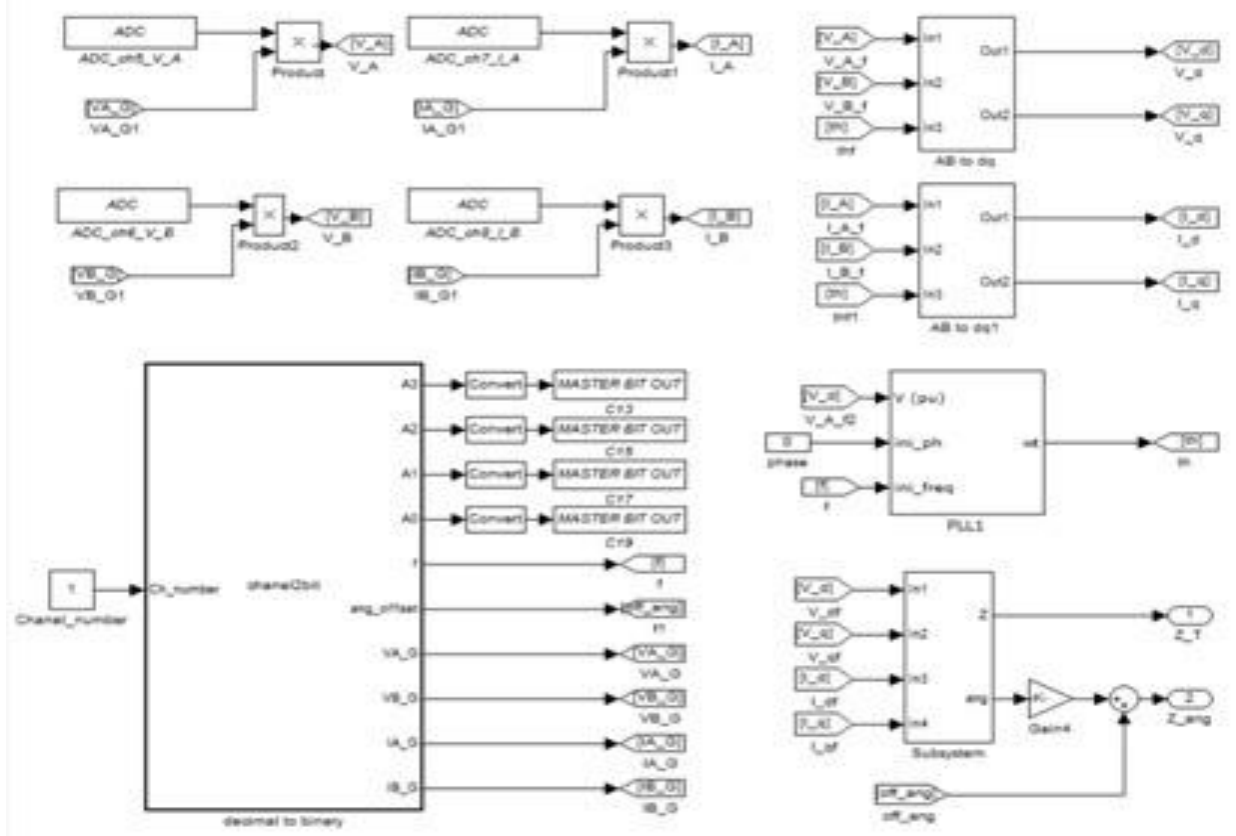

Fig. E.1 MATLAB simulink model for impedance calculation in dSPACE1104

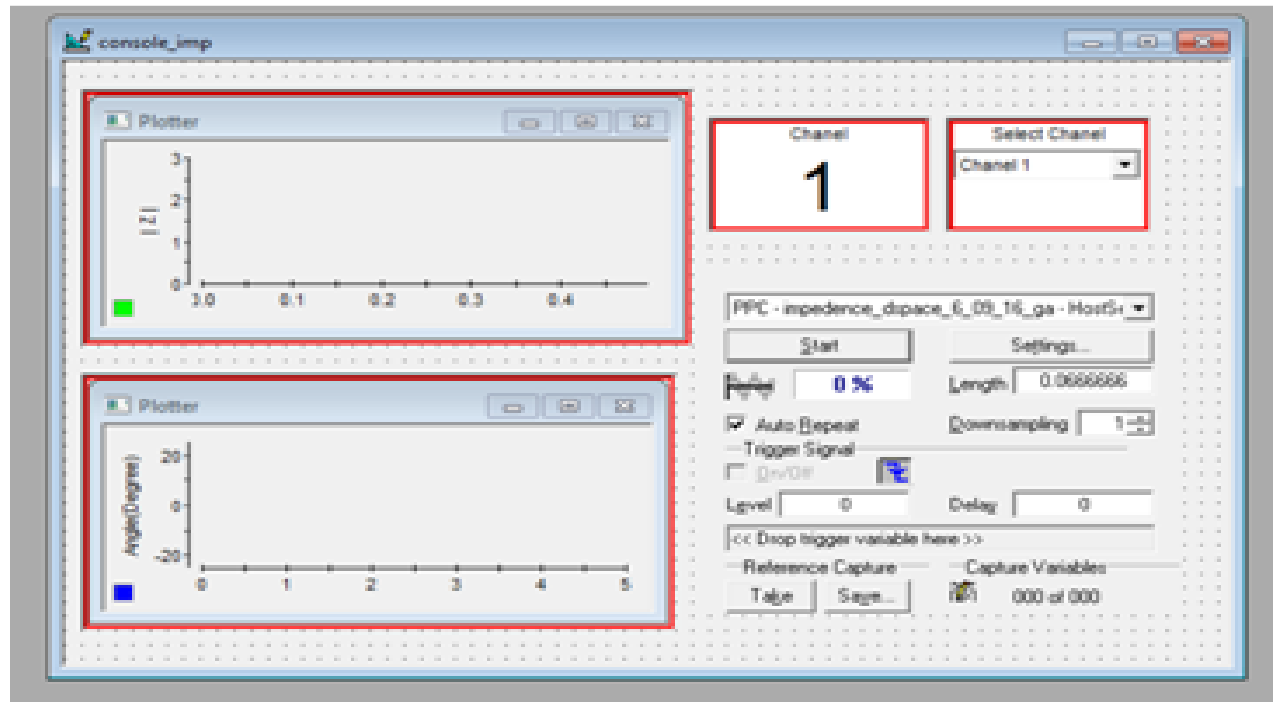

Fig. E.2 dSPACE1104 console to display measurement result 